\title{
NEW EVIDENCE ON THE CONVERGENCE OF INTERNATIONAL INCOME FROM A GROUP OF 29 COUNTRIES
}

\author{
John W. Dawson* \\ Appalachian State University \\ and \\ Amit Sen ${ }^{+}$ \\ Xavier University
}

\begin{abstract}
This paper updates and extends the time-series evidence on the convergence of international incomes using a set of 29 countries over the period 1900-2001. Time-series tests for stochastic convergence are supplemented with tests which provide evidence on the notion of " $\beta$-convergence" predicted by the Solow model. The evidence indicates that the relative income series of 21 countries are consistent with stochastic convergence, and that $\beta$-convergence has occurred in at least 16 countries at some point during the $20^{\text {th }}$ century. Further examination of the properties of the $\beta$-convergence test provides anecdotal evidence of conditional convergence in three additional countries for which the convergence hypothesis was initially rejected. Consideration of convergence clubs strengthens the evidence in favor of convergence. Analysis of the cross-country dispersion of incomes over time also suggests that convergence has occurred over the 1900-2001 period, particularly within certain clubs, with structural breaks associated with World War II in many countries causing a break in the convergence process.
\end{abstract}

JEL Codes: C32, O40

Keywords: Growth, Convergence, Convergence Clubs, Unit-Root Tests, Structural Breaks

* Corresponding Author: Department of Economics, Appalachian State University, P.O. 32051, Boone, NC 28608-2051. Phone: (828) 262-6128, Fax: (828) 262-6105, Email: dawsonjw@appstate .edu. We wish to thank Mark Strazicich and an anonymous referee for useful comments and discussions.

+ Department of Economics, 3800 Victory Parkway, Xavier University, Cincinnati, OH 45207-3212. Phone: (513) 745-2931, Fax: (513) 745-3692, Email: sen@xavier . edu. This author acknowledges support from a Williams Intellectual Contributions Development Summer Grant at Xavier University. 


\section{Introduction}

Convergence-the notion that a country’s income level will approach a "steady-state” level conditional on certain country characteristics-is a central prediction of the Solow (1956) model. ${ }^{1}$ Since the resurgence of interest in growth theory over the past two decades, numerous studies have provided empirical tests of the convergence hypothesis. The first tests of convergence were crosssectional studies which involved regressions of long-run growth rates on initial income levels and other explanatory variables. See, for example, Baumol (1986), Barro (1991), and Barro and Sala-iMartin (1992), among others. These studies generally support the convergence hypothesis in large samples of countries. Friedman (1992), however, criticized cross-section tests of convergence which involve regressing growth rates on initial income levels. This criticism gave rise to a new class of time-series tests of convergence.

Many time-series tests of convergence are based on the notion of "stochastic" convergence first suggested by Carlino and Mills (1993). Stochastic convergence implies that shocks to the income of a given country relative to the average income across a set of countries will be temporary. Thus, a common test for stochastic convergence involves testing for a unit root in the log of the ratio of per capita income relative to the group average. Failure to reject the unit-root null hypothesis is evidence against convergence. Rejection of the unit-root null hypothesis, on the other hand, is taken as evidence in favor of convergence. The existing time-series evidence is generally supportive of stochastic convergence. See, for example, studies by Carlino and Mills (1993), Loewy and Papell (1996), Li and Papell (1999), and Strazicich, Lee, and Day (2004).

This paper has several objectives. First, given the difficulties in finding long income series for a large number of countries, existing time-series studies have been restricted to small samples including either U.S. regions or subsets of OECD countries. This paper extends the time-series tests

\footnotetext{
${ }^{1}$ More specifically, two notions of convergence from the growth literature are "absolute” and “conditional” convergence. Absolute convergence implies that incomes across countries are approaching the same steady-state level, whereas conditional convergence implies "compensating differentials” in a country's steady-state level based on cross-country differences in saving rates, technology, population growth, etc. Throughout this paper, our use of the term “convergence” without a qualifying adjective refers to conditional convergence.
} 
of convergence to a group of 29 countries over the period 1900-2001 using data recently reported in Maddison (2003). In comparison to Li and Papell (1999), for example, we examine thirteen more countries with thirteen additional years of data for all countries. We find evidence of stochastic convergence in 21 of the 29 countries in our sample.

Second, a subtle but important point is to recognize that the evidence of stochastic convergence provided in existing time-series studies is a necessary, but not sufficient, condition for the notion of convergence implied by growth theory, known as “ $\beta$-convergence.” This point was originally made by Carlino and Mills (1993), who suggest an additional time-series test for convergence. Specifically, if per capita incomes are converging, then regression of the log relative income on an intercept and trend should produce opposite signs on their estimated coefficients. We use this test to determine which countries' relative income series are converging conditionally, and show that the "opposite-signs" condition is only a valid test for absolute convergence. We reconsider the properties of the test in the context of conditional convergence, and examine the implications in the cross-country data. To our knowledge, this is the first application of this test using cross-country income data. The results provide evidence of $\beta$-convergence in 16 countries, and anecdotal evidence of conditional convergence in three additional countries for which the test formally rejects the convergence hypothesis. In addition, analysis of convergence clubs strengthens the evidence in favor of convergence.

Finally, in his criticism of cross-country tests for convergence, Friedman (1992, p. 2129) notes that Hotelling (1933) suggests that the "real test of a tendency to convergence would be in showing a consistent diminution of variance...among individual [countries].” We close our empirical results by providing such evidence. We find that the coefficient of variation in income across countries generally declines throughout the sample with the exception of an increase during the World War II period. The remainder of the paper is organized as follows. Section 2 discusses unit-root tests for stochastic convergence and presents empirical results. Section 3 discusses the test for $\beta$-convergence suggested by Carlino and Mills (1993) and provides empirical evidence on 
convergence for our selection of countries. Section 4 offers some concluding remarks.

\section{Testing for Stochastic Convergence}

In this section, we test for stochastic convergence across the 29 countries for which annual data over the period 1900-2001 are available from Maddison (1995, 2003). These countries include Argentina, Australia, Austria, Belgium, Brazil, Canada, Chile, Columbia, Denmark, Finland, France, Germany, India, Italy, Japan, Mexico, the Netherlands, New Zealand, Norway, Peru, Portugal, Spain, Sri Lanka, Sweden, Switzerland, the United Kingdom, the United States, Uruguay, and Venezuela. ${ }^{2}$ We use several versions of unit-root tests to evaluate the stochastic convergence hypothesis, where evidence against the unit-root null hypothesis is consistent with stochastic convergence. These unit-root tests are applied to the relative per capita real GDP series for each country, measured as the individual country’s per capita GDP as a percentage of the aggregate per capita GDP of the group. Specifically, we take the natural logarithm of the ratio of the individual country's per capita real GDP to the aggregate per capita real GDP of the group, where the later is calculated by dividing the aggregate real GDP of all 29 countries by the total population of these countries. The relative per capita real GDP series for each of the 29 countries are shown in Figures 1-29.

\subsection{Using Standard Unit-Root Tests}

We first calculate conventional augmented Dickey-Fuller (ADF) unit-root tests for the relative per capita real GDP series for each country. Specifically, we run the following two regressions:

$$
\begin{aligned}
& y_{t}=\hat{\mu}+\hat{\alpha} y_{t-1}+\sum_{j=1}^{k^{*}} \hat{c}_{j} \Delta y_{t-j}+\hat{e}_{t} \\
& y_{t}=\hat{\mu}+\hat{\beta} t+\hat{\alpha} y_{t-1}+\sum_{j=1}^{k^{*}} \hat{c}_{j} \Delta y_{t-j}+\hat{e}_{t},
\end{aligned}
$$

where $y_{t}$ denotes the relative real per capita GDP for an individual country. Regression (1) is used

\footnotetext{
${ }^{2}$ See the Appendix for details on the construction of the data.
} 
to the test for the presence of a unit root against the stationary alternative in which the relative real per capita GDP fluctuates around a constant mean (possibly non-zero). Regression (2) tests for a unit-root against the trend-stationary alternative. The unit-root statistic is the $t$-statistic on the first lag of relative income, namely, $y_{t-1}$. The unit-root statistic from regression (1) is denoted by $t_{\mu}$, and that from regression (2) is denoted by $t_{\tau}$. The extra $k^{*}$ regressors $\left\{\Delta y_{t-j}\right\}_{j=1}^{k^{*}}$ are included in the regression to account for additional correlation in the time series $\left\{y_{t}\right\}_{t=1}^{T}$. In practice, the value of the lag-truncation parameter $\left(k^{*}\right)$ is unknown, and so a data-dependent method for choosing the appropriate value of $k^{*}$ is used. In this paper, we use Perron and Vogelsang's (1992) k(t-sig) method for selecting the lag-truncation parameter. First, we specify an upper bound 'kmax' for the lagtruncation parameter. ${ }^{3}$ The chosen value of $k^{*}$ is then determined according to the following 'general-to-specific' procedure: the last lag in an autoregression of order $k^{*}$ is significant, but the last lag in an autoregression of order greater than $k^{*}$ is insignificant. The significance of the coefficient is assessed using the $10 \%$ critical values based on a standard normal distribution. The significance of the unit-root statistics, $t_{\mu}$ and $t_{\tau}$, are evaluated using the finite sample ( $\left.T=100\right)$ critical values given in Banerjee, Dolado, Galbraith, and Hendry (1993), Table 4.2, p. 103. The calculated unit-root statistics for relative per capita real GDP for all countries are reported in Table 1.

Based on the ADF tests with trend, we are able to reject the unit-root null hypothesis in favor of the trend-stationary alternative for the following ten countries: Argentina, Brazil, Columbia, Denmark, Finland, France, Germany, the Netherlands, Norway, and the U.S. In addition, we can reject the unit-root null for Australia and Belgium based on the ADF test without trend. ${ }^{4}$ Thus, the unit-root null can be rejected in 12 of the 29 countries using the ADF test. In comparison, Li and Papell (1999) report evidence of convergence for 10 countries using ADF tests in their sample of 16 countries. However, it is well known that conventional ADF unit-root tests often fail to reject

\footnotetext{
${ }^{3}$ Throughout the paper, we use kmax=8 unless specified otherwise.

${ }^{4}$ Estimates of the trend coefficients in the relative income series for these countries are statistically insignificant in the estimation of (2).
} 
the unit-root null hypothesis when there is a break in the trend function under the stationary alternative hypothesis. ${ }^{5}$ Thus, we next consider unit-root statistics that are designed to have power against the trend-break stationary alternative.

\subsection{Allowing Structural Breaks}

In this section, we consider unit-root tests that allow for a simultaneous break in the intercept and slope of the trend function (called the "Mixed” Model). ${ }^{6}$ First, we briefly describe the unit-root statistics that are designed to have power against the trend-break stationary alternative characterized by the Mixed Model. Consider the time series $\left\{y_{t}\right\}_{t=1}^{T}$. It is assumed that the location of the break or "break-date" is unknown. Under the unit-root null hypothesis, the data generating process is given by:

$$
y_{t}=\mu_{0}+y_{t-1}+e_{t} .
$$

The data generating process under the Mixed Model characterization of the trend-break stationary alternative is given by:

$$
y_{t}=\mu_{0}+\mu_{1} D U_{t}\left(T_{b}\right)+\mu_{2} t+\mu_{3} D T_{t}\left(T_{b}\right)+\alpha y_{t-1}+e_{t},
$$

where $T_{b}$ is the break-date, $D U_{t}\left(T_{b}\right)$ is the intercept-break dummy that is equal to 0 if $t \leq T_{b}$ and 1 if $t>T_{b}, D T_{t}\left(T_{b}\right)$ is the slope-break dummy that is equal to 0 if $t \leq T_{b}$ and $\left(t-T_{b}\right)$ if $t>T_{b}$, and $e_{t}$ is a stationary zero-mean process. We assume that $T_{b}=[\lambda T]$ for some $\lambda \in \Lambda=\left[\lambda_{0}, 1-\lambda_{0}\right]$, where [.] is the smallest integer function. We assume that the break-date is unknown. Therefore, for each possible break-date in the sample, namely, $T_{b} \in\left\{\left[\lambda_{0} T\right],\left[\lambda_{0} T\right]+1, \ldots, T-\left[\lambda_{0} T\right]\right\}$, we estimate the following regressions that nest the unit-root null and the appropriate trend-break stationary alternative given in (4) as:

\footnotetext{
${ }^{5}$ See, for example, Perron (1989, 1997), Banerjee, Lumsdaine, and Stock (1992), Zivot and Andrews (1992), and Vogelsang and Perron (1998) for further details.

${ }^{6}$ An alternative form of the break under the trend-break stationary alternative is one that only allows for a break in the intercept (referred to as the "Crash” Model). Sen (2003) shows that a loss of power occurs when the form of the break is incorrectly specified under the alternative, and suggests using the more general Mixed Model when the true form of the break is unknown.
} 


$$
y_{t}=\hat{\mu}_{0}+\hat{\mu}_{1} D U_{t}\left(T_{b}\right)+\hat{\mu}_{2} t+\hat{\mu}_{3} D T_{t}\left(T_{b}\right)+\hat{\alpha} y_{t-1}+\sum_{j=1}^{k^{*}} \hat{c}_{j} \Delta y_{t-j}+\hat{e}_{t} .
$$

The additional $k^{*}$ regressors, $\left\{\Delta y_{t-j}\right\}_{j=1}^{k^{*}}$, are included in the regression to account for additional correlation in the time series $\left\{y_{t}\right\}_{t=1}^{T}$, and the value of the lag-truncation parameter $\left(k^{*}\right)$ is determined using Perron and Vogelsang’s (1992) k(t-sig) data-dependent method described above.

The estimated regression (5) is used to calculate the sequence of $t$-statistics for $H_{0}: \alpha=1$, denoted by $\left\{t_{D F}\left(T_{b}\right)\right\}_{T_{b}=\left[\lambda_{0} T\right]}^{T-\left[\lambda_{0} T\right]}$. Based on this sequence of $t$-statistics, a number of minimum- $t$ statistics can be obtained by using an algorithm to choose the appropriate break-date that maximizes evidence against $H_{0}: \alpha=1$. We consider two particular algorithms for choosing the break-date. The first statistic, originally proposed by Perron and Vogelsang (1992) and Zivot and Andrews (1992), is obtained by choosing the break-date that maximizes evidence against the unit root null, that is:

$$
t_{D F}^{\min }=\operatorname{Min}_{T_{b} \in\left\{\left[\lambda_{0} T\right],\left[\lambda_{0} T\right]+1, \ldots, T-\left[\lambda_{0} T\right]\right\}} t_{D F}\left(T_{b}\right) .
$$

Asymptotic critical values for $t_{D F}^{\min }$ can be obtained from Table 4 of Zivot and Andrews (1992), and the corresponding finite sample critical values can be obtained from Table 1 of Perron (1997). The second statistic proposed by Banerjee, Lumsdaine, and Stock (1992) and Vogelsang and Perron (1998) is defined as:

$$
\hat{t}_{D F}=t_{D F}(\hat{\lambda})
$$

where $\hat{\lambda}$ is the break-date that maximizes the F-statistic, $F_{T}([\lambda T])$, corresponding to $H_{0}: \mu_{1}=0, \mu_{3}=0$. Finite sample critical values for $\hat{t}_{D F}$ can be found in Table 3 of Vogelsang and Perron (1998).

Finally, we calculate a version of the supWald statistic proposed by Murray and Zivot (1998) for the joint null hypothesis $H_{0}^{J}: \alpha=1, \mu_{1}=0, \mu_{3}=0$. The estimated regressions in (5) are used to calculate the $F$-statistic for this hypothesis, denoted by $\left\{F_{T}\left(T_{b}\right)\right\}_{T_{b}=\left[\lambda_{0} T\right]}^{T-\left[\lambda_{0} T\right]}$, where:

$$
F_{T}\left(T_{b}\right)=\frac{\left[R \hat{\mu}\left(T_{b}\right)\right]^{\prime}\left[R V^{-1} R^{\prime}\right]^{-1}\left[R \hat{\mu}\left(T_{b}\right)\right]}{q \hat{\sigma}^{2}\left(T_{b}\right)} .
$$

$\hat{\mu}\left(T_{b}\right)$ is the OLS estimator of $\mu=\left(\mu_{0}, \mu_{1}, \mu_{2}, \mu_{3}, \alpha, c_{1}, \ldots, c_{k}\right)^{\prime}, V=\sum_{t=1}^{T} x_{t}\left(T_{b}\right) x_{t}\left(T_{b}\right)^{\prime}, \mathrm{r}=(0,0,1)^{\prime}$, 
$\hat{\sigma}^{2}\left(T_{b}\right)=(T-5-k)^{-1} \sum_{t=1}^{T}\left[y_{t}-x_{t}\left(T_{b}\right)^{\prime} \hat{\mu}\left(T_{b}\right)\right]^{2}, \quad q=3$ is the number of restrictions, and $R$ is defined so that $R \mu=r$ corresponds to the restrictions imposed on the parameter vector $\mu$ by the joint null $H_{0}^{J}: \mu_{1}=0, \mu_{3}=0, \alpha=1$. Specifically,

$$
R=\left[\begin{array}{llllll}
0 & 1 & 0 & 0 & 0 & 0_{k}^{\prime} \\
0 & 0 & 0 & 1 & 0 & 0_{k}^{\prime} \\
0 & 0 & 0 & 0 & 1 & 0_{k}^{\prime}
\end{array}\right]
$$

where $0_{k}^{\prime}$ is a $(k \times 1)$ vector of zeros. The maximum- $F$-statistic, denoted by $F_{T}^{\max }$, is calculated as:

$$
F_{T}^{\max }=\operatorname{Max}_{T_{b} \in\left\{\left[\lambda_{0} T\right],\left[\lambda_{0} T\right]+1, \ldots, T-\left[\lambda_{0} T\right]\right\}} F_{T}\left(T_{b}\right)
$$

based on the sequence of $F$-statistics $\left\{F_{T}\left(T_{b}\right)\right\}_{T_{b}=\left[\lambda_{0} T\right]}^{T-\left[\lambda_{0} T\right]}$; see Sen (2003) for details. The critical values for the $F_{T}^{\max }$ statistic can be found in Table 1 of Sen (2003).

The results for the relative real per capita GDP series for each country using the Mixed Model statistics are shown in Tables 3 and 4. For each country, we report the unit-root statistics, the implied estimated break-dates, and the estimate trend-function coefficients at the estimated break-date. The critical values of all unit-root statistics, $t_{D F}^{\min }, \hat{t}_{D F}$, and $F_{T}^{\max }$, are given in Table 2 for convenience.

Based on the $t_{D F}^{\min }, \hat{t}_{D F}$, and $F_{T}^{\max }$ statistics reported in Table 3, we can reject the unit-root null hypothesis for 16 countries: Austria, Belgium, Brazil, Canada, Chile, Denmark, Finland, France, Italy, the Netherlands, New Zealand, Norway, Spain, Switzerland, Uruguay, and Venezuela. Compared to the ADF tests, the unit-root tests that allow for a break under the trend-stationary alternative provide evidence in favor of stochastic convergence for nine additional countries (Austria, Canada, Chile, Italy, New Zealand, Spain, Switzerland, Uruguay, and Venezuela). Thus, the ADF and Mixed Model unit-root tests together are able to provide evidence of stochastic convergence in 21 of the 29 countries. We are unable to reject the unit-root null hypothesis at the 10\% level of significance using either test for India, Japan, Mexico, Peru, Portugal, Sri Lanka, 
Sweden, and the United Kingdom.

In comparing our results to those of Li and Papell (1999), they find evidence of stochastic convergence in 14 of the 16 OECD countries considered in their study over the period 1900-1989. They are unable to reject the unit-root null only for Italy and Sweden. Of the 16 countries included in their study, we find evidence of stochastic convergence in 13 of them, having failed to reject the unit-root null only for Japan, Sweden, and the U.K. Possible explanations for the different results for Italy, Japan, and the U.K. are the use of different unit-root tests and a different sample period. ${ }^{7}$

In closing the discussion of stochastic convergence, we note that among the 16 countries for which we reject the unit-root null hypothesis in favor of the Mixed Model, the estimated break-date for six countries (Belgium, Canada, Denmark, France, the Netherlands, and Norway) is 1939. For an additional four countries (Italy, New Zealand, Switzerland, and Venezuela), the estimated breakdate falls within the 1940-45 period. Thus, it appears that World War II is the most frequently identified source of structural breaks among the countries in our sample. ${ }^{8}$

\section{Testing for " $\beta$-Convergence"}

As noted in the introduction, stochastic convergence is a necessary, but not sufficient, condition for conditional convergence. Therefore, in this section, we supplement the tests for stochastic convergence with additional tests to determine whether conditional convergence is

\footnotetext{
${ }^{7}$ One other possible explanation is that more evidence of convergence may be found in groups of more similar countries such as the group of OECD countries considered by Li and Papell (1999) (i.e., the notion of so-called "convergence clubs”). We explore this possibility in Section 3.3.

${ }^{8}$ Following the suggestion of an anonymous referee, we also performed tests for stochastic convergence assuming a known break in 1945 (i.e., assuming $T_{b}=1945$ ). The advantage of such an approach is higher power than in the unknown-break case. The evidence in favor of stochastic convergence, however, was not as strong in the known-break case, with only 10 countries rejecting the unit-root null. (These are not the same 10 countries for which we estimate breaks during the war period, but there is considerable overlap.) The most likely explanation for weaker results, we believe, is that even though breaks occur for a number of countries during the war period from 1939-1945, there is some variation in the exact date of the breaks within this period. Thus, we refer to the World War II period in discussing the timing of the most frequently observed break-dates (as opposed to any particular year within this period). Further evidence along these lines is presented in Section 3.4 with respect to " $\sigma$-convergence." Given the results for stochastic convergence, we do not pursue the known-break case further.
} 
occurring. Carlino and Mills (1993) suggest estimating the intercept and trend coefficients for the relative income series in countries for which there is evidence of stochastic convergence. A finding that the intercept and trend coefficients have opposite signs indicates that countries whose relative per capita income is initially above the group average is trending (converging) down toward the average, and vice versa. Carlino and Mills refer to this notion of convergence as " $\beta$-convergence," a term introduced by Baumol (1986). A number of studies have used this test for $\beta$-convergence; see, for example, Tomljanovich and Vogelsang (2002) and Nieswiadomy and Strazicich (2004). Ours, however, is the first study to consider this test for $\beta$-convergence in a cross-country setting. In the discussion that follows, we will refer to this test as the "trend test" for convergence.

\subsection{Properties of the "Trend Test"}

In addition to the evidence of $\beta$-convergence suggested by an intercept and trend of opposite signs in the trend test, several other possibilities are noted in Tomljanovich and Vogelsang (2002) and Nieswiadomy and Strazicich (2004). One possibility is an intercept that is significantly different from zero with a trend that is not. This evidence reportedly suggests that income in the country in question has already converged (conditionally) to its steady state level. Another possibility is an intercept that is not significantly different from zero and a trend that is, which is said to suggest that a country's income is diverging. Finally, if neither the intercept nor the trend is significant, there is evidence that absolute convergence is occurring. Of course, a finding that the intercept and slope coefficients have the same sign apparently indicates divergence.

In the discussion that follows, we reconsider the implications of the trend test for convergence. Carlino and Mills use the following simple time-series representation for relative income:

$$
R I_{i t}=R I_{i}^{e}+u_{i t},
$$

where $R I_{i t}$ is the relative real per capita GDP of country $i$ at time $t, R I_{i}^{e}$ is the time-invariant steadystate differential for country $i$, and $u_{i t}$ represents deviations from the steady-state differential. For 
a particular country, the deviations $u_{t}$ consist of a deterministic linear trend and a stochastic process such that $u_{t}=v_{0}+\beta t+v_{t}$, where $v_{0}$ is the initial deviation from the steady state and $\beta$ is the deterministic rate of convergence (for ease in exposition, we suppress the subscript for country $i$ from this point forward). Carlino and Mills argue that " $\beta$-convergence requires that if a [country] is above its compensating differential initially, i.e., $v_{0}>0$, it should grow more slowly than the [world], i.e., $\beta<0$. Similarly, if $v_{0}<0, \beta>0$ " (p. 337). The difficulty in applying this observation empirically, however, is that $v_{0}$ is not observed. In particular, substituting the process for $u_{t}$ in (11), we obtain

$$
R I_{t}=\mu+\beta t+v_{t},
$$

where $\mu=R I^{e}+v_{0}$. Estimates of $\mu$ in (12) do not separately identify $R I^{e}$ and $v_{0}$.

When (12) is estimated empirically, finding $\mu$ and $\beta$ to be of opposite signs indicates convergence in cases where $R I^{e}$ and $v_{0}$ are of the same sign. That is, in cases where a country's steady-state differential is above the group average (i.e., $R I^{e}>0$ ) and the country is initially above its steady-state differential $\left(v_{0}>0\right)$, there is no question that $\mu>0$ and convergence will imply $\beta<$ 0 . Similarly, when $R I^{e}<0$ and $v_{0}<0$, we will have $\mu<0$ and convergence will imply $\beta>0$. However, in cases where $R I^{e}$ and $v_{0}$ are of opposite signs, it is possible that $\mu$ and $\beta$ could have the same sign even when convergence is occurring. This corresponds to cases where a country's steadystate differential is above the world average $\left(R I^{e}>0\right)$, but the country is initially below its differential $\left(v_{0}<0\right)$, and vice versa for the case where $R I^{e}<0$ and $v_{0}>0$. In particular, when $R I^{e}$ and $v_{0}$ have opposite signs, $\mu$ and $\beta$ will be of opposite signs under convergence only when the magnitude of the initial deviation $v_{0}$ is large relative to the magnitude of $R I^{e}$. The implication is that a country, for example, approaching a positive steady-state differential from below will produce the result $\mu>0, \beta>0$ when $v_{0}$ is relatively small. Thus, a finding that $\mu$ and $\beta$ have the same sign may also be consistent with convergence.

Carlino and Mills note the possibility that $R I^{e}$ and $v_{0}$ may be of opposite signs (see their 
footnote 1), but fail to articulate that, in general, this will result in $\mu$ and $\beta$ having the same signs under convergence (i.e., they refer to a positive relationship between $\mu$ and $\beta$ under convergence as the exception rather than the rule). As stated above, $\mu$ and $\beta$ will tend to have the same sign except in the case where $v_{0}$ is sufficiently large. Likewise, a finding that $\mu=0$ and $\beta \neq 0$ may also be consistent with convergence in the case where $R I^{e}$ and $v_{0}$ are opposite in sign but similar in magnitude.

Following Carlino and Mills, the discussion above assumes that $R I^{e} \neq 0$. That is, the notion of convergence in question is conditional convergence. Absolute convergence, on the other hand, implies that all countries have the same steady state, so that $R I^{e}=0$ for all countries. In this case, there is no cross-country variation in $R I^{e}$, and differences in $\mu$ in cross-country estimates of (12) will reflect differences in $v_{0}$ only. Thus, under the assumption of absolute convergence, $\mu$ and $\beta$ will have opposite signs. Finding $\mu$ and $\beta$ to have the same sign, therefore, will be sufficient to reject the hypothesis of absolute convergence. However, such a finding is not sufficient to rule out conditional convergence. Unfortunately, such a finding may also be consistent with divergence, leaving the conclusion in testing for conditional convergence vs. divergence ambiguous. ${ }^{9}$

In discussing their empirical results, Carlino and Mills report that the possibility of $\mu$ and $\beta$ having the same signs "is counterfactual" (see, again, their footnote 1). Since they consider convergence among regions in the U.S., however, the relevant form of convergence may be absolute convergence, since regions within the U.S. are likely to have similar characteristics and, thus, may be approaching the same steady state. A similar argument applies to the analysis of Tomljanovich

\footnotetext{
${ }^{9}$ It may seem that the test for stochastic convergence rules out the possibility of divergence. However, stochastic convergence implies rejecting the unit-root null hypothesis in favor of the trend-stationary alternative. Thus, the relative income series can trend indefinitely (i.e., diverge) away from the world average under the notion of stochastic convergence. A test that the relative income series is mean-stationary would preclude such a possibility, and this may be the motivation in testing for what Li and Papell (1999) call "deterministic" convergence. Testing for deterministic convergence involves testing the unit-root null against the mean-stationary alternative (that is, not including a trend term in the unit-root test). The downside of such a test is that not including a trend when one is present biases the estimate of the unit-root statistic. This is similar to the problem in using the Crash Model when the Mixed Model is the true form of break; see Sen (2003) for further discussion. Indeed, in cases where the transition period is sufficiently long, the relative income series may have a trend for long periods of time under convergence.
} 
and Vogelsang (2002), who also consider convergence across regions in the U.S. In testing for convergence across countries where different characteristics are more likely to give rise to steady state differentials, however, conditional convergence is more likely the relevant form of convergence and a finding of "same signs" is a more distinct possibility.

In summary, a finding that $\mu$ and $\beta$ have opposite signs indicates that absolute convergence or conditional convergence may be occurring. A finding that $\mu$ and $\beta$ have the same signs indicates that conditional convergence or divergence may be occurring. In other words, there may be more evidence of conditional convergence than is revealed by application of the opposite-signs condition as suggested by Carlino and Mills. Furthermore, since we know something about the circumstances in which conditional convergence is consistent with $\mu$ and $\beta$ having the same signs, a case-by-case examination of the time-series $R I_{t}$ may provide some anecdotal evidence on the issue of conditional convergence vs. divergence. For instance, in cases where a country's steady state differential is above the group average (i.e., $R I^{e}>0$ ), a negative shock to the relative income series which leaves the country below its differential immediately following the shock (implying an "initial" deviation $v_{0}<0$ ) and subsequent conditional convergence would imply positive estimates of $\mu$ and $\beta$. Below we argue that such is the case for many countries following shocks associated with World War II.

\subsection{Estimation and Results}

We now turn to estimating the intercept and trend coefficients for the "trend test" for convergence. Some studies use separate OLS regressions to estimate the intercept and trend coefficients required to test for conditional convergence. See, for example, the application of Nieswiadomy and Strazicich (2004). Alternatively, the necessary estimates of the intercept and trend coefficients may be obtained from the results of the unit-root tests for stochastic convergence. In addition to the intercept and trend coefficients of interest, these equations include the first lag of the dependent variable and lagged first differences of the dependent variable. Since these additional variables serve to control for serial correlation in the dependent variable, one could argue that these variables are necessary to correctly determine the statistical significance of the intercept and trend 
coefficients, and that using separate regressions which do not control for serial correlation could lead to flawed inference. ${ }^{10}$ The unit-root test results also provide estimates of the dummies for breaks in the intercept and trend for countries in which a trend break is found to be statistically significant. This allows for an application of the trend test in both the pre- and post-break periods for these countries.

One problem that does arise in using the Mixed Model results to assess the significance of the required intercept and trend coefficients is that the distributions of estimated trend function parameters are non-standard. Thus, we cannot use critical values from the standard $t$ and $F$ distributions to determine the statistical significance of these parameters. Sen (2005) shows that the appropriate critical values for testing these estimated parameters depend on the location of the break and the values of the parameters themselves. Therefore, we approximate the critical values of the tests needed to evaluate the significance of the pre- and post-break intercept and trend coefficients using simulations with a sample size of 100 observations and 10,000 replications. Specifically, we generate data based on the Mixed Model unit-root test equation in (4). For each country, the estimated break date reported in Table 4 is used for $T_{b}$ and $e_{t} \sim$ i.i.d. $\mathrm{N}(0,1)$. The lag truncation parameter (introduced in equation (1)) is set to zero in generating the data, with kmax $=0$ used in the estimation of the critical values so that the true lag truncation parameter (i.e., $k^{*}=0$ ) is used. The parameter for which critical values are being estimated is set to zero in the data generating process, with the estimated coefficients reported in Table 4 used for all other parameters. The critical values of the test statistics used to evaluate the significance of the pre- and post-break intercept and trend coefficients are calculated for the estimated break-date implied by the various unit-root statistics. ${ }^{11}$ These approximate critical values are used in evaluating the trend test results reported below for countries with breaks. For countries without breaks, the standard $t$-distribution applies to the

\footnotetext{
${ }^{10}$ Specifically, the presence of serial correlation will result in unbiased parameter estimates but inflated t-scores for the estimates, thus causing spurious rejections of the null hypothesis that estimated coefficients are zero.

${ }^{11}$ The GAUSS program and results are available from the authors upon request.
} 
intercept and trend coefficients estimated in ADF tests.

The estimates of the intercept and slope coefficients required for the trend test are reported in Table 4 for countries found to have structural breaks and Table 1 for countries with no breaks. For countries with breaks, a comparison of $\hat{\mu}_{0}$ (the pre-break intercept) and $\hat{\mu}_{2}$ (the pre-break trend) from Table 4 is required to determine convergence in the pre-break period. Similarly, a comparison of the post-break intercept, $\hat{\mu}_{0}+\hat{\mu}_{1}+\hat{\mu}_{2}\left(\hat{T}_{b}-1899-k^{*}-1\right)$, and the post-break trend, $\hat{\mu}_{2}+\hat{\mu}_{3}$, is required to determine convergence in the post-break period. For countries without breaks, a comparison of $\hat{\mu}$ and $\hat{\beta}$ from Table 1 is required. The required information is compiled in Table 5 along with the resulting conclusion regarding convergence based on the "opposite-signs" condition discussed in the previous section. As a general rule, we rely on information from Table 4 for countries in which we find evidence of a statistically significant trend break using the Mixed Model unit-root test. For countries without a significant trend break, we turn to information from the ADF unit-root test with trend reported in Table 1 . Note that if the only rejection of the unit-root null hypothesis occurs in the ADF unit-root test without trend, the implication is a zero trend and, thus, that the country has already reached its steady state.

A total of 21 countries are considered in Table 5. These are the 21 countries for which we reported evidence of stochastic convergence above. The results reported in Table 5 suggest that 11 of the 21 countries are currently (in the post-break period) converging or have already reached a steady state. There is evidence of convergence or having already reached a steady state at some point during the $1900-2001$ period in 16 of the 21 countries. There are only five countries for which there is no evidence of convergence over the 1900-2001 period using the trend test. These include Denmark, Finland, Germany, Norway, and the U.S. In addition, there is no evidence of convergence for Austria during the 1954-2001 period and Belgium, Canada, France, and the Netherlands during 1940-2001. We now take a closer look at convergence in these countries which do not meet the criteria for convergence by strict application of the opposite-signs condition in the trend test.

Recall from the discussion above that the trend test, strictly speaking, is a test for absolute 
convergence, and that a finding of intercept and trend coefficients of the same sign does not necessarily rule out the possibility of conditional convergence. Of particular interest is the fact that two of the five countries for which there is no evidence of convergence based on the trend testDenmark and Norway-experience breaks in 1939 and involve estimates for the intercept and trend coefficients which are both positive in the post-war period. Such a finding is consistent with a shock which leaves the countries initially below their positive steady state differentials, but conditionally converging toward the differential. Visual inspection of the relative income series in Figures 9 and 19 indicates that just such a shock might have occurred in these countries around World War II. Similar reasoning applies in the cases of Belgium, Canada, France, and the Netherlands in the postwar period, and in Austria following a break in 1953.

Other cases in which the "opposite-signs” condition is not met may also indicate behavior consistent with conditional convergence. Recall from the discussion above that a finding of an intercept that is insignificantly different from zero along with a non-zero trend does not necessarily rule out conditional convergence, as a country with a steady state differential and initial deviation that are similar in magnitude but opposite in signs will give rise to such a result under conditional convergence. Such a possibility occurs in the pre- and post-break periods for Finland, and in the pre-break period in Norway. Thus, anecdotal evidence suggests there may be more evidence of conditional convergence than is suggested by a strict application of the trend test. Taken together, the evidence suggests conditional convergence may have occurred in as many as 19 countries at some point during the $20^{\text {th }}$ century.

\subsection{Convergence "Clubs” Considered"}

In this section, we examine whether or not more evidence of convergence exists among groups of countries that are similar with respect to economic characteristics-that is, whether or not convergence "clubs" exist, following the use of the term introduced by Baumol (1986). It seems

\footnotetext{
${ }^{12}$ We would like to thank an anonymous referee for suggesting this line of inquiry that resulted in a stronger case for convergence.
} 
particularly important to consider such a possibility given the heterogeneous nature of the 29 countries in our dataset. In addition, most previous studies which have looked at convergence across countries using time-series tests have focused exclusively on OECD countries. It is important to determine whether this particular grouping affects the findings with regard to convergence.

We consider three possible clubs, all of which are subsets of our original group of 29 countries: (1) an OECD club consisting of the 19 OECD countries; (2) a European club consisting of the 14 European countries; and (3) a Latin American club consisting of the eight countries from South and Central America. These clubs were selected because of economic (in the case of the OECD club) and geographic (in the case of the European and Latin American clubs) similarities among the 29 countries in our original sample. For the analysis of each club, we redefine the relative income series for each country with respect to aggregate real per capita income for all countries within the club.

We first calculate tests for stochastic convergence in the clubs using the same methodology as for the full 29-country group presented above. ${ }^{13}$ In the OECD club, we find that 16 of the 19 countries are stochastically converging; Australia, Japan and the U.K. are the exceptions. Australia was found to exhibit evidence of stochastic convergence in our original analysis of the full 29country sample. Japan and the U.K., however, were also found not to exhibit evidence of stochastic convergence in the full sample analysis. Two other OECD countries-Portugal and Sweden-were among the group for which there was no evidence of stochastic convergence in the full sample, but are found to exhibit stochastic convergence within the OECD club. Thus, there is slightly more evidence of stochastic convergence in the OECD club than was found among the OECD countries in the full sample.

Similar results are obtained for the European club, where 12 of 14 countries are found to exhibit stochastic convergence (Norway and the U.K. being the exceptions). From the earlier

\footnotetext{
${ }^{13}$ In the interest of conserving space and not over-burdening the reader with tedious details, we do not report estimates of the unit-root tests for stochastic convergence for the clubs. These results are available from the authors upon request.
} 
analysis of the full sample, three European countries (Portugal, Sweden, and the U.K.) were found not to exhibit evidence of stochastic convergence. In the analysis of the Latin American club, five of eight countries exhibit evidence of stochastic convergence (Peru, Uruguay, and Venezuela are the exceptions). This represents slightly less evidence of stochastic convergence than in the analysis of the full sample, where only two of the countries from this club were found not to exhibit stochastic convergence (Mexico and Peru). Thus, the results are mixed as to whether more evidence of stochastic convergence is found using the clubs, with slightly more evidence of stochastic convergence in the OECD and European clubs and slightly less in the Latin American club.

We now turn to the evidence on $\beta$-convergence within the three clubs. Here we once again use the "trend" test of Carlino and Mills (1993) as described above in the analysis of the full sample of countries. The results for the OECD, European, and Latin American clubs are presented in Tables $6 \mathrm{~A}, 6 \mathrm{~B}$, and 6C, respectively. The last column of the tables provides easy reference to instances of more or less evidence of convergence than was found in the full sample (as reported in Table 5). For the OECD club, there is substantially more evidence of convergence than was found in the analysis of the full sample, with 14 new instances of convergence (or having reached a steady state) and only 2 new instances of divergence. In total, evidence of convergence is found for 16 of the 19 OECD countries at some point during the 1900-2001 period. This includes seven countries for which there was no evidence of convergence in the analysis of the full sample in Table 5 (these include Denmark, Finland, Germany, Norway, Portugal, Sweden, and the U.S.).

In addition, the results for the OECD club indicate convergence in eight cases where the trend test provided ambiguous results in the full sample results of Table 5. These include the cases of Austria, Belgium, Canada, Denmark, Finland, France, the Netherlands, and Norway. Recall that these were cases which resulted in intercept and slope coefficients violating the opposite signs requirement for convergence suggested by Carlino and Mills (1993). We argued above, however, that such findings may be consistent with convergence in a group of heterogenous countries; see the discussion in section 3.1 for more details. The results for the OECD club confirm that convergence 
may indeed occur in such cases. Application of the trend test is more likely to provide the "opposite signs" result within the OECD club because the countries in the club are more likely to tend toward similar steady states in the long run.

Estimates of the trend test for the European club reported in Table 6B provide the same general conclusion, with considerably more evidence of convergence within the club than in the full sample of countries. Here, as indicated in the last column of the table, there are eight new instances of convergence and only two new instances of divergence. Again, most of the new instances of convergence confirm the possibility of convergence in countries with ambiguous results in the analysis of the full sample.

Analysis of the Latin American club suggests about the same evidence of convergence as was found for countries in that region in the analysis of the full sample; see the results in Table 6C. Two new instances of convergence (both in Mexico) are offset by two new cases of divergence (in Uruguay and Venezuela). Note that most of the new evidence on convergence in the OECD and European clubs involved countries for which there were ambiguous conclusions in the analysis of the full sample. None of the Latin American countries provided ambiguous conclusions in the full sample analysis, thus providing a possible explanation for the largely unchanged results in the club analysis.

\subsection{Evidence on " $\sigma$-convergence"}

One last piece of evidence in favor of convergence is provided by examination of the variance of real per capita GDP across countries. Following the suggestion in Friedman (1992), convergence implies a "consistent diminution of variance" across countries. This type of convergence is sometimes referred to as $\sigma$-convergence. Figure 30 presents the coefficient of variation (CV) of real per capita GDP for the 29 countries in our sample and the three clubs 
considered above. ${ }^{14}$ The World War II period (1939-1945) is shaded. The CV series for all 29 countries exhibits a steady decline from roughly 1920 through the mid-1930s and from 1945-1980; the estimated trend of the series is negative and statistically significant during both of these subperiods. This behavior is evidence of absolute convergence prior to and following World War II. The increase in the series during the 1939-1945 period is further evidence that shocks experienced by a large number of countries during the War caused a break in the convergence process. It is interesting to note, however, that the convergence which has occurred since World War II has not yet reduced the CV to its pre-war level (achieved in 1934).

The CV series for the European, OECD, and Latin American clubs display some interesting behavior in comparison to the series for the full sample. First, the dramatic increase in cross-country income variation associated with the World War II period appears in all three clubs. Second, the convergence process is apparently further along in the European and OECD clubs than in the Latin American club and the full sample, as indicated by the lower levels achieved by the OECD and European CV series. Third, the estimated trends of the series are significantly negative for all three clubs in both the pre-war and post-war periods. However, the rate of convergence is clearly faster during the post-war period. Finally, the increase in the CV series for the full sample during the mid1980s is primarily attributable to a break in the convergence process in the Latin American countries during this time. This period is identified as a time of debt crisis and economic collapse for many countries in this region (see, e.g., Hopenhayn and Neumeyer (2004)).

\section{Conclusion}

This paper examines the time-series evidence on the convergence of international incomes in a group of 29 countries over the 1900-2001 period. The first test of convergence is a test of stochastic convergence, which amounts to a test of the unit-root hypothesis in the relative per capita

\footnotetext{
${ }^{14}$ See Nieswiadomy and Strazicich (2004) and deJuan and Tomljanovich (2005) for recent examples of analyses of convergence using a series similar to our CV series.
} 
income series for a country. Rejection of the unit-root null hypothesis is evidence in favor of stochastic convergence. In addition to the standard Dickey-Fuller test, we use versions of unit-root tests that allow for a structural break in the intercept and time-trend of the series. We find evidence of stochastic convergence in 21 of the 29 countries. Significant trend breaks are found in 16 of the 21 countries for which we provide evidence of stochastic convergence. Breaks occurring during the World War II period (1939-1945) are found in 10 countries.

Carlino and Mills (1993) suggest that stochastic convergence is a necessary, but not sufficient, condition for the notion of convergence-known as $\beta$-convergence-implied by the Solow (1956) growth model. To provide a test for $\beta$-convergence, Carlino and Mills suggest estimating the intercept and trend of the relative income series in a country. Opposite signs on the estimated intercept and slope coefficients is suggested as evidence of $\beta$-convergence. We argue that, strictly speaking, this “opposite-signs” condition only applies in the case of absolute convergence, and that violation of this condition can be consistent with the notion of conditional convergence. Thus, the test suggested by Carlino and Mills may understate the evidence in favor of conditional convergence across countries. Such understatements are more likely to occur in diverse groups of countries where the countries tend toward different steady states in the long run.

Use of the Carlino and Mills test based on the “opposite-signs” condition suggests that there is evidence of convergence in 16 countries. Further examination of several countries for which we find the same signs on the intercept and trend coefficients suggests that shocks associated with World War II may have caused behavior consistent with a finding of the same signs under convergence, thus providing anecdotal evidence of conditional convergence in three additional countries for which the convergence hypothesis was originally rejected. Application of the test in groups of economically and geographically similar countries (i.e., convergence “clubs”) confirms that convergence is occurring in each of the cases where ambiguous results are found initially.

Finally, examination of the coefficient of variation in real per capita income levels across countries provides further evidence of convergence with breaks during World War II and confirms 
the findings with respect to convergence within the clubs. 


\section{Data Appendix}

All data are from Maddison (2003), with the following exceptions to maintain border consistency throughout the sample period.

Germany: Data from the 1900-1994 period are from Maddison (1995), based on German boundaries in 1989. Data from 1995-2001 are determined by applying growth rates implicit in the Maddison (2003) data to the (1995) data, since the (2003) data are based on current boundaries for the reunified Germany.

United Kingdom: Data from Maddison (2003), except that data for 1921-2001 were adjusted to include Ireland to maintain consistency with the pre-1921 data. Figures for the U.K. and Ireland were summed for 1921-2001 using data for each country from Maddison (2003).

India: Data from Maddison (2003), except that data for the 1947-2001 time period were adjusted to include Bangladesh and Pakistan to maintain consistency with the pre-1947 data. Figures for India, Bangladesh and Pakistan are summed for the 1947-2001 period, using data on each country from Maddison (2003) with the following exceptions. The growth rates of GDP and population from 1946-47 implicit in Maddison (1995) are applied to the 1946 figure in Maddison (2003) to obtain GDP and population figures for 1947. Population figures from 1948-49 are obtained by adding population estimates for India, Bangladesh, and Pakistan from Maddison (1995). 
Table 1. ADF Tests for Relative Per Capita GDP, 1900-2001

\begin{tabular}{|c|c|c|c|c|c|c|c|c|c|}
\hline \multirow[b]{2}{*}{ Series } & \multicolumn{4}{|c|}{ Without Trend } & \multicolumn{5}{|c|}{ With Trend } \\
\hline & $\mathrm{k}^{*}$ & $t_{\mu}$ & $\mu$ & $\alpha$ & $\mathrm{k}^{*}$ & $t_{\tau}$ & $\mu$ & $\beta$ & $\alpha$ \\
\hline Argentina & 8 & -0.3394 & -0.0083 & 0.9896 & 1 & $-3.6346^{c}$ & 0.1166 & -0.0014 & 0.7945 \\
\hline Australia & 1 & $-2.9216^{c}$ & 0.1114 & 0.8488 & 1 & -2.8757 & 0.1125 & -0.0000 & 0.8480 \\
\hline Austria & 0 & -1.5084 & 0.0229 & 0.9462 & 0 & -2.4764 & -0.0004 & 0.0008 & 0.8945 \\
\hline Belgium & 1 & $-2.5990^{d}$ & 0.0520 & 0.9112 & 1 & -2.9922 & 0.0483 & 0.0003 & 0.8935 \\
\hline Brazil & 7 & -1.0114 & -0.0089 & 0.9786 & 2 & $-3.8691^{b}$ & -0.2200 & 0.0014 & 0.7936 \\
\hline Canada & 5 & -1.5967 & 0.0355 & 0.9511 & 5 & -3.2032 & 0.0790 & 0.0006 & 0.8430 \\
\hline Chile & 0 & -2.2312 & -0.0022 & 0.9041 & 0 & -2.4981 & 0.0151 & -0.0004 & 0.8650 \\
\hline Columbia & 1 & $-3.4506^{b}$ & -0.0831 & 0.8541 & 1 & $-3.5724^{c}$ & -0.0976 & 0.0001 & 0.8392 \\
\hline Denmark & 5 & -1.3962 & 0.0406 & 0.9454 & 3 & $-4.9252^{\mathrm{a}}$ & 0.1512 & 0.0013 & 0.6837 \\
\hline Finland & 4 & -0.1609 & 0.0094 & 0.9976 & 3 & $-4.0711^{\mathrm{a}}$ & -0.0630 & 0.0025 & 0.7763 \\
\hline France & 4 & -1.7710 & 0.0343 & 0.9383 & 3 & $-3.6872^{c}$ & 0.0388 & 0.0010 & 0.8297 \\
\hline Germany & 1 & -1.9777 & 0.0388 & 0.9334 & 3 & $-3.2720^{\mathrm{d}}$ & 0.0429 & 0.0009 & 0.8383 \\
\hline India & 5 & -1.5987 & -0.0397 & 0.9783 & 5 & 0.9106 & 0.0123 & 0.0007 & 1.0330 \\
\hline Italy & 2 & -1.1785 & 0.0139 & 0.9732 & 1 & -2.7683 & -0.0084 & 0.0008 & 0.8975 \\
\hline Japan & 0 & -0.2328 & 0.0122 & 0.9966 & 0 & -1.8067 & -0.0392 & 0.0010 & 0.9452 \\
\hline Mexico & 0 & -2.2074 & -0.0299 & 0.9057 & 0 & -2.2740 & -0.0359 & 0.0001 & 0.9012 \\
\hline Netherlands & 1 & $-3.4389^{b}$ & 0.1047 & 0.8326 & 1 & $-3.8947^{b}$ & 0.0999 & 0.0005 & 0.7972 \\
\hline New Zealand & 6 & -1.3738 & 0.0406 & 0.9338 & 6 & -1.8830 & 0.1061 & -0.0004 & 0.8654 \\
\hline Norway & 1 & -0.8334 & 0.0123 & 0.9866 & 1 & $-4.4557^{\mathrm{a}}$ & -0.0113 & 0.0024 & 0.7624 \\
\hline Peru & 2 & -1.1336 & -0.0275 & 0.9580 & 2 & -1.0433 & -0.0062 & -0.0004 & 0.9616 \\
\hline Portugal & 0 & 0.6971 & 0.0105 & 1.0105 & 0 & -2.5142 & -0.0684 & 0.0011 & 0.9274 \\
\hline Spain & 6 & -0.4571 & 0.0043 & 0.9905 & 6 & -1.3572 & -0.0161 & 0.0004 & 0.9664 \\
\hline Sri Lanka & 3 & -1.8615 & -0.0312 & 0.9728 & 3 & -0.2044 & -0.0237 & 0.0003 & 0.9942 \\
\hline Sweden & 5 & -0.8398 & 0.0123 & 0.9863 & 5 & -1.7432 & 0.0202 & 0.0005 & 0.9306 \\
\hline Switzerland & 3 & -1.8414 & 0.0472 & 0.9471 & 1 & -3.1394 & 0.0840 & 0.0004 & 0.8794 \\
\hline U.K. & 0 & -2.4235 & 0.0539 & 0.9202 & 0 & -1.7431 & 0.0457 & 0.0000 & 0.9288 \\
\hline U.S. & 4 & -1.8102 & 0.0615 & 0.9370 & 7 & $-3.2037^{d}$ & 0.1383 & 0.0004 & 0.8320 \\
\hline Uruguay & 3 & -1.0491 & -0.0028 & 0.9659 & 3 & -2.2714 & 0.0472 & -0.0008 & 0.8724 \\
\hline Venezuela & 1 & -1.7703 & 0.0070 & 0.9768 & 4 & -0.4839 & 0.0301 & -0.0005 & 0.9914 \\
\hline
\end{tabular}

Notes: Finite sample ( $\mathrm{T}=100)$ critical values are taken from Table 4.2, p. 103, in Banerjee, Dolado, Galbraith, and Hendry (1993). Critical values for the ADF unit-root tests $\left(t_{\mu}\right)$ without trend are: -2.58 at the $10 \%$ level, -2.89 at the $5 \%$ level, -3.17 at the $2.5 \%$ level, and -3.51 at the $1 \%$ level. Critical values for the ADF unit-root tests with trend $\left(t_{\tau}\right)$ are: -3.15 at the $10 \%$ level, -3.45 at the $5 \%$ level, -3.73 at the $2.5 \%$ level, and -4.04 at the $1 \%$ level. Superscripts a, b, c, and d denote significance at the $1 \%, 2.5 \%, 5 \%$, and $10 \%$ levels, respectively. 
Table 2. Asymptotic Critical Values for $t_{D F}^{\min }, \hat{t}_{D F}$, and $F_{T}^{\max }$

\begin{tabular}{llll}
\hline Level & $t_{D F}^{\min }$ & $\hat{t}_{D F}$ & $F_{T}^{\max }$ \\
\hline $1 \%$ & -6.21 & -5.93 & 13.08 \\
$2.5 \%$ & -5.86 & -5.60 & 11.92 \\
$5 \%$ & -5.55 & -5.26 & 10.88 \\
$10 \%$ & -5.25 & -4.90 & 9.87 \\
\hline Notes: We use $\lambda_{0}=0.05$ for $\hat{t}_{D F}$ and $F_{T}^{\max }$. & The finite sample critical values for \\
$t_{D F}^{\text {min }}$ are obtained from Table 1 of Perron (1997). The finite sample critical values \\
for $\hat{t}_{D F}$ are obtained from Table 3 of Vogelsang and Perron (1998). The finite \\
sample $(\mathrm{T}=100)$ critical values for $F_{T}^{\text {max }}$ are taken from Table 1 of Sen (2003).
\end{tabular}


Table 3. Mixed Model Unit-Root Tests for Relative Per Capita Output, 1900-2001

\begin{tabular}{|c|c|c|c|c|c|c|}
\hline Series & $t_{D F}^{\min }$ & $\hat{T}_{b}\left(t_{D F}^{\min }\right)$ & $\hat{t}_{D F}$ & $\hat{T}_{b}\left(\hat{t}_{D F}\right)$ & $F_{T}^{\max }$ & $\hat{T}_{b}\left(F_{T}^{\max }\right)$ \\
\hline Argentina & -5.0401 & 1945 & -4.8441 & 1943 & 8.6306 & 1943 \\
\hline Australia & -4.0788 & 1976 & -3.9022 & 1931 & 8.0243 & 1931 \\
\hline Austria & -5.0614 & 1953 & $-5.0614^{d}$ & 1953 & 8.9656 & 1953 \\
\hline Belgium & $-6.4113^{a}$ & 1939 & $-6.4113^{a}$ & 1939 & $13.8279^{a}$ & 1939 \\
\hline Brazil & $-5.5102^{d}$ & 1973 & $-4.9123^{d}$ & 1977 & $10.6494^{\mathrm{d}}$ & 1973 \\
\hline Canada & $-5.6764^{c}$ & 1939 & $-5.6764^{b}$ & 1939 & $11.5166^{\mathrm{c}}$ & 1939 \\
\hline Chile & -4.9639 & 1972 & $-4.9639^{d}$ & 1972 & 9.3287 & 1972 \\
\hline Columbia & -4.7376 & 1929 & -4.7376 & 1929 & 7.7045 & 1929 \\
\hline Denmark & $-6.3009^{a}$ & 1938 & $-5.9865^{a}$ & 1939 & $13.5217^{\mathrm{a}}$ & 1938 \\
\hline Finland & $-5.4437^{d}$ & 1924 & -4.6233 & 1918 & $15.9642^{\mathrm{a}}$ & 1918 \\
\hline France & -5.1760 & 1939 & $-5.1760^{d}$ & 1939 & $10.1478^{d}$ & 1944 \\
\hline Germany & -4.3180 & 1953 & -2.8600 & 1946 & 7.1323 & 1946 \\
\hline India & -2.7541 & 1971 & -2.7541 & 1971 & 8.3044 & 1971 \\
\hline Italy & -4.5890 & 1940 & -2.0641 & 1945 & $10.9305^{c}$ & 1945 \\
\hline Japan & -3.7006 & 1940 & 0.5181 & 1945 & 6.7088 & 1945 \\
\hline Mexico & -4.1445 & 1944 & -4.0123 & 1943 & 7.2765 & 1943 \\
\hline Netherlands & $-5.6376^{c}$ & 1939 & $-5.6376^{\mathrm{b}}$ & 1939 & $10.6785^{d}$ & 1939 \\
\hline New Zealand & -5.1961 & 1944 & $-5.1961^{d}$ & 1944 & 9.5014 & 1944 \\
\hline Norway & $-5.2738^{d}$ & 1939 & $-5.2738^{c}$ & 1939 & 9.5146 & 1939 \\
\hline Peru & -4.4954 & 1964 & -4.4857 & 1965 & 7.2605 & 1965 \\
\hline Portugal & -4.8377 & 1938 & -4.8377 & 1938 & 8.0191 & 1938 \\
\hline Spain & $-8.0658^{a}$ & 1935 & $-8.0658^{a}$ & 1935 & $22.9739^{\mathrm{a}}$ & 1935 \\
\hline Sri Lanka & -3.7777 & 1961 & -3.7398 & 1970 & 6.1967 & 1970 \\
\hline Sweden & -4.3604 & 1944 & -4.3604 & 1944 & 7.5505 & 1944 \\
\hline Switzerland & $-7.1496^{a}$ & 1944 & $-7.1496^{\mathrm{a}}$ & 1944 & $19.2395^{\mathrm{a}}$ & 1944 \\
\hline U.K. & -3.2820 & 1968 & -3.1781 & 1965 & 3.9938 & 1968 \\
\hline U.S. & -4.5803 & 1938 & -4.5790 & 1939 & 7.6790 & 1939 \\
\hline Uruguay & -4.9303 & 1961 & $-4.9303^{d}$ & 1961 & 8.4080 & 1961 \\
\hline Venezuela & -5.0363 & 1943 & $-5.0363^{d}$ & 1943 & 9.1583 & 1943 \\
\hline
\end{tabular}

Notes: The superscripts a, b, c, and d denote significance at the $1 \%, 2.5 \%, 5 \%$ and $10 \%$ significance levels. 
Table 4. Mixed Model Unit-Root Tests for Relative Per Capita Output, 1900-2001

\begin{tabular}{|c|c|c|c|c|c|c|c|c|}
\hline Series & $\hat{T}_{b}$ & $\mathrm{k}^{*}$ & $\hat{\mu}_{0}$ & $\hat{\mu}_{1}$ & $\hat{\mu}_{2}$ & $\hat{\mu}_{3}$ & $\hat{\alpha}$ & $\hat{\sigma}^{2}$ \\
\hline \multirow[t]{3}{*}{ Argentina } & 1943 & 7 & 0.2489 & 0.0658 & -0.0026 & -0.0023 & 0.4994 & 0.0475 \\
\hline & & & $(4.711)$ & $(3.091)$ & $(-3.087)$ & $(-2.299)$ & $(-4.844)$ & \\
\hline & 1945 & 7 & $\begin{array}{l}0.2767 \\
(4.816)\end{array}$ & $\begin{array}{l}0.0641 \\
(2.834)\end{array}$ & $\begin{array}{l}-0.0026 \\
(-3.087)\end{array}$ & $\begin{array}{l}-0.0031 \\
(-3.040)\end{array}$ & $\begin{array}{c}0.4355 \\
(-5.040)\end{array}$ & 0.0475 \\
\hline \multirow[t]{2}{*}{ Australia } & 1931 & 1 & $\begin{array}{l}0.1921 \\
(4.209)\end{array}$ & $\begin{array}{l}0.0336 \\
(2.844)\end{array}$ & $\begin{array}{l}-0.0023 \\
(-3.794)\end{array}$ & $\begin{array}{l}0.0023 \\
(3.693)\end{array}$ & $\begin{array}{c}0.7854 \\
(-3.902)\end{array}$ & 0.0266 \\
\hline & 1976 & 1 & $\begin{array}{l}0.1885 \\
(4.085)\end{array}$ & $\begin{array}{l}-0.0061 \\
(-0.468)\end{array}$ & $\begin{array}{l}-0.0003 \\
(-2.040)\end{array}$ & $\begin{array}{l}0.0022 \\
(2.552)\end{array}$ & $\begin{array}{c}0.7579 \\
(-4.079)\end{array}$ & 0.0274 \\
\hline Austria & 1953 & 3 & $\begin{array}{l}0.1958 \\
(3.980)\end{array}$ & $\begin{array}{l}0.1619 \\
(3.632)\end{array}$ & $\begin{array}{l}-0.0044 \\
(-3.401)\end{array}$ & $\begin{array}{l}0.0096 \\
(3.889)\end{array}$ & $\begin{array}{c}0.5257 \\
(-5.061)\end{array}$ & 0.0880 \\
\hline Belgium & 1939 & 3 & $\begin{array}{l}0.2472 \\
(5.897)\end{array}$ & $\begin{array}{l}-0.1122 \\
(-4.838)\end{array}$ & $\begin{array}{l}-0.0002 \\
(-0.331)\end{array}$ & $\begin{array}{l}0.0037 \\
(4.097)\end{array}$ & $\begin{array}{c}0.5828 \\
(-6.411)\end{array}$ & 0.0400 \\
\hline \multirow[t]{2}{*}{ Brazil } & 1973 & 2 & $\begin{array}{l}-0.3889 \\
(-5.481)\end{array}$ & $\begin{array}{l}0.0785 \\
(3.516)\end{array}$ & $\begin{array}{l}0.0024 \\
(5.218)\end{array}$ & $\begin{array}{l}-0.0040 \\
(-3.687)\end{array}$ & $\begin{array}{c}0.6355 \\
(-5.510)\end{array}$ & 0.0371 \\
\hline & 1977 & 6 & $\begin{array}{l}-0.5760 \\
(-4.908)\end{array}$ & $\begin{array}{c}0.0947 \\
(3.280)\end{array}$ & $\begin{array}{l}0.0037 \\
(5.056)\end{array}$ & $\begin{array}{l}-0.0062 \\
(-3.865)\end{array}$ & $\begin{array}{c}0.4606 \\
(-4.912)\end{array}$ & 0.0376 \\
\hline Canada & 1939 & 5 & $\begin{array}{l}0.2338 \\
(5.380)\end{array}$ & $\begin{array}{l}0.0997 \\
(4.683)\end{array}$ & $\begin{array}{l}-0.0021 \\
(-2.942)\end{array}$ & $\begin{array}{l}0.0028 \\
(3.372)\end{array}$ & $\begin{array}{c}0.6314 \\
(-5.676)\end{array}$ & 0.0333 \\
\hline Chile & 1972 & 0 & $\begin{array}{c}0.0444 \\
(2.585)\end{array}$ & $\begin{array}{l}-0.1651 \\
(-4.024)\end{array}$ & $\begin{array}{l}-0.0008 \\
(-2.096)\end{array}$ & $\begin{array}{l}0.0083 \\
(4.444)\end{array}$ & $\begin{array}{c}0.6427 \\
(-4.964)\end{array}$ & 0.0638 \\
\hline Columbia & 1929 & 1 & $\begin{array}{l}-0.1493 \\
(-4.469)\end{array}$ & $\begin{array}{l}0.0415 \\
(2.595)\end{array}$ & $\begin{array}{l}-0.0004 \\
(-0.486)\end{array}$ & $\begin{array}{l}0.0001 \\
(0.094)\end{array}$ & $\begin{array}{c}0.7608 \\
(-4.738)\end{array}$ & 0.0323 \\
\hline \multirow[t]{2}{*}{ Denmark } & 1938 & 3 & $\begin{array}{l}0.1928 \\
(5.688)\end{array}$ & $\begin{array}{l}-0.0663 \\
(-3.554)\end{array}$ & $\begin{array}{l}0.0030 \\
(3.810)\end{array}$ & $\begin{array}{l}-0.0005 \\
(-0.726)\end{array}$ & $\begin{array}{c}0.5729 \\
(-6.301)\end{array}$ & 0.0398 \\
\hline & 1939 & 7 & $\begin{array}{l}0.2855 \\
(5.718)\end{array}$ & $\begin{array}{l}-0.0895 \\
(-4.305)\end{array}$ & $\begin{array}{l}0.0044 \\
(4.388)\end{array}$ & $\begin{array}{l}-0.0009 \\
(-1.077)\end{array}$ & $\begin{array}{c}0.3857 \\
(-5.987)\end{array}$ & 0.0393 \\
\hline \multirow[t]{2}{*}{ Finland } & 1918 & 3 & $\begin{array}{c}0.0101 \\
(0.462)\end{array}$ & $\begin{array}{l}0.0989 \\
(4.519)\end{array}$ & $\begin{array}{l}-0.0092 \\
(-3.946)\end{array}$ & $\begin{array}{l}0.0123 \\
(4.893)\end{array}$ & $\begin{array}{c}0.7153 \\
(-4.623)\end{array}$ & 0.0375 \\
\hline & 1924 & 3 & $\begin{array}{l}-0.0435 \\
(-2.268)\end{array}$ & $\begin{array}{l}0.0765 \\
(3.288)\end{array}$ & $\begin{array}{l}-0.0027 \\
(-1.719)\end{array}$ & $\begin{array}{l}0.0071 \\
(3.414)\end{array}$ & $\begin{array}{c}0.5963 \\
(-5.444)\end{array}$ & 0.0400 \\
\hline
\end{tabular}


Table 4 (Continued). Mixed Model Unit-Root Tests for Relative Per Capita Output, 1900-2001

\begin{tabular}{|c|c|c|c|c|c|c|c|c|}
\hline Series & $\hat{T}_{b}$ & $\mathrm{k}^{*}$ & $\hat{\mu}_{0}$ & $\hat{\mu}_{1}$ & $\hat{\mu}_{2}$ & $\hat{\mu}_{3}$ & $\hat{\alpha}$ & $\hat{\sigma}^{2}$ \\
\hline France & 1939 & 8 & $\begin{array}{c}0.1333 \\
(3.680)\end{array}$ & $\begin{array}{l}-0.1327 \\
(-3.621)\end{array}$ & $\begin{array}{l}0.0026 \\
(1.854)\end{array}$ & $\begin{array}{l}0.0026 \\
(1.697)\end{array}$ & $\begin{array}{c}0.5681 \\
(-5.176)\end{array}$ & 0.0661 \\
\hline \multirow[t]{2}{*}{ Germany } & 1946 & 3 & $\begin{array}{l}0.0932 \\
(2.881)\end{array}$ & $\begin{array}{l}0.0667 \\
(2.296)\end{array}$ & $\begin{array}{l}-0.0014 \\
(-1.680)\end{array}$ & $\begin{array}{l}0.0024 \\
(1.971)\end{array}$ & $\begin{array}{c}0.8198 \\
(-2.860)\end{array}$ & 0.0659 \\
\hline & 1953 & 3 & $\begin{array}{l}0.1262 \\
(3.473)\end{array}$ & $\begin{array}{l}0.0720 \\
(2.381)\end{array}$ & $\begin{array}{l}-0.0007 \\
(-1.054)\end{array}$ & $\begin{array}{l}0.0024 \\
(2.021)\end{array}$ & $\begin{array}{c}0.7169 \\
(-4.318)\end{array}$ & 0.0664 \\
\hline India & 1971 & 4 & $\begin{array}{l}-0.2033 \\
(-2.943)\end{array}$ & $\begin{array}{l}-0.0263 \\
(-1.241)\end{array}$ & $\begin{array}{l}-0.0028 \\
(-2.942)\end{array}$ & $\begin{array}{l}0.0075 \\
(3.912)\end{array}$ & $\begin{array}{c}0.8139 \\
(-2.754)\end{array}$ & 0.0363 \\
\hline \multirow[t]{2}{*}{ Italy } & 1940 & 1 & $\begin{array}{c}0.0177 \\
(0.961)\end{array}$ & $\begin{array}{l}-0.0612 \\
(-2.263)\end{array}$ & $\begin{array}{c}0.0007 \\
(0.812)\end{array}$ & $\begin{array}{l}0.0032 \\
(2.909)\end{array}$ & $\begin{array}{c}0.7528 \\
(-4.589)\end{array}$ & 0.0560 \\
\hline & 1945 & 2 & $\begin{array}{l}0.0530 \\
(3.081)\end{array}$ & $\begin{array}{l}0.1036 \\
(4.063)\end{array}$ & $\begin{array}{l}-0.0024 \\
(-3.474)\end{array}$ & $\begin{array}{l}0.0028 \\
(2.532)\end{array}$ & $\begin{array}{c}0.8877 \\
(-2.064)\end{array}$ & 0.0526 \\
\hline \multirow[t]{2}{*}{ Japan } & 1940 & 2 & $\begin{array}{l}-0.0946 \\
(-2.663)\end{array}$ & $\begin{array}{l}-0.0944 \\
(-2.617)\end{array}$ & $\begin{array}{l}0.0022 \\
(1.881)\end{array}$ & $\begin{array}{l}0.0029 \\
(2.037)\end{array}$ & $\begin{array}{c}0.8229 \\
(-3.701)\end{array}$ & 0.0720 \\
\hline & 1945 & 0 & $\begin{array}{l}0.0510 \\
(1.379)\end{array}$ & $\begin{array}{l}0.1371 \\
(3.621)\end{array}$ & $\begin{array}{l}-0.0022 \\
(-2.372)\end{array}$ & $\begin{array}{l}-0.0000 \\
(-0.030)\end{array}$ & $\begin{array}{c}1.0289 \\
(0.518)\end{array}$ & 0.0696 \\
\hline \multirow[t]{2}{*}{ Mexico } & 1943 & 0 & $\begin{array}{l}-0.0378 \\
(-2.338)\end{array}$ & $\begin{array}{c}0.0577 \\
(3.570)\end{array}$ & $\begin{array}{l}-0.0022 \\
(-3.530)\end{array}$ & $\begin{array}{l}0.0024 \\
(3.033)\end{array}$ & $\begin{array}{c}0.7671 \\
(-4.012)\end{array}$ & 0.0380 \\
\hline & 1944 & 0 & $\begin{array}{l}-0.0427 \\
(-2.633)\end{array}$ & $\begin{array}{c}0.0602 \\
(3.555)\end{array}$ & $\begin{array}{l}-0.0022 \\
(-3.480)\end{array}$ & $\begin{array}{l}0.0024 \\
(3.015)\end{array}$ & $\begin{array}{c}0.7501 \\
(-4.145)\end{array}$ & 0.0382 \\
\hline Netherlands & 1939 & 3 & $\begin{array}{l}0.2234 \\
(4.772)\end{array}$ & $\begin{array}{l}-0.1422 \\
(-3.704)\end{array}$ & $\begin{array}{l}0.0020 \\
(1.612)\end{array}$ & $\begin{array}{l}0.0016 \\
(1.202)\end{array}$ & $\begin{array}{c}0.5762 \\
(-5.638)\end{array}$ & 0.0731 \\
\hline New Zealand & 1944 & 5 & $\begin{array}{l}0.4250 \\
(4.963)\end{array}$ & $\begin{array}{l}0.1189 \\
(4.234)\end{array}$ & $\begin{array}{l}-0.0031 \\
(-3.335)\end{array}$ & $\begin{array}{l}-0.0002 \\
(-0.275)\end{array}$ & $\begin{array}{c}0.5070 \\
(-5.196)\end{array}$ & 0.0466 \\
\hline Norway & 1939 & 1 & $\begin{array}{l}-0.0217 \\
(-1.496)\end{array}$ & $\begin{array}{l}-0.0490 \\
(-2.646)\end{array}$ & $\begin{array}{l}0.0037 \\
(4.202)\end{array}$ & $\begin{array}{l}-0.0001 \\
(-0.210)\end{array}$ & $\begin{array}{c}0.7043 \\
(-5.274)\end{array}$ & 0.0420 \\
\hline \multirow[t]{2}{*}{ Peru } & 1964 & 6 & $\begin{array}{l}-0.4832 \\
(-4.328)\end{array}$ & $\begin{array}{c}0.0143 \\
(0.479)\end{array}$ & $\begin{array}{l}0.0052 \\
(4.080)\end{array}$ & $\begin{array}{l}-0.0162 \\
(-4.275)\end{array}$ & $\begin{array}{c}0.4240 \\
(-4.495)\end{array}$ & 0.0647 \\
\hline & 1965 & 6 & $\begin{array}{l}-0.4897 \\
(-4.319)\end{array}$ & $\begin{array}{c}0.0051 \\
(0.172)\end{array}$ & $\begin{array}{l}0.0052 \\
(4.080)\end{array}$ & $\begin{array}{l}-0.0166 \\
(-4.236)\end{array}$ & $\begin{array}{c}0.4151 \\
(-4.486)\end{array}$ & 0.0647 \\
\hline
\end{tabular}


Table 4 (Continued). Mixed Model Unit-Root Tests for Relative Per Capita Output, 1900-2001

\begin{tabular}{|c|c|c|c|c|c|c|c|c|}
\hline Series & $\hat{T}_{b}$ & $\mathrm{k}^{*}$ & $\hat{\mu}_{0}$ & $\hat{\mu}_{1}$ & $\hat{\mu}_{2}$ & $\hat{\mu}_{3}$ & $\hat{\alpha}$ & $\hat{\sigma}^{2}$ \\
\hline Portugal & 1938 & 2 & $\begin{array}{l}-0.1798 \\
(-4.882)\end{array}$ & $\begin{array}{l}-0.0647 \\
(-2.969)\end{array}$ & $\begin{array}{l}0.0010 \\
(1.421)\end{array}$ & $\begin{array}{l}0.0045 \\
(3.416)\end{array}$ & $\begin{array}{c}0.7031 \\
(-4.838)\end{array}$ & 0.0449 \\
\hline \multirow[t]{2}{*}{ Spain } & 1935 & 6 & -0.0461 & -0.2114 & 0.0017 & 0.0046 & 0.6567 & 0.0369 \\
\hline & & & $(-3.002)$ & $(-7.285)$ & $(2.003)$ & $(4.583)$ & $(-8.066)$ & \\
\hline \multirow[t]{4}{*}{ Sri Lanka } & 1961 & 0 & -0.1031 & -0.0662 & -0.0021 & 0.0053 & 0.8092 & 0.0377 \\
\hline & & & $(-4.128)$ & $(-2.928)$ & $(-3.329)$ & $(4.226)$ & $(-3.778)$ & \\
\hline & 1970 & 3 & -0.1276 & -0.0412 & -0.0032 & 0.0081 & 0.7455 & 0.0371 \\
\hline & & & $(-3.954)$ & $(-1.818)$ & $(-3.677)$ & (3.886) & $(-3.740)$ & \\
\hline Sweden & 1944 & 7 & $\begin{array}{l}0.0449 \\
(2.866)\end{array}$ & $\begin{array}{c}0.0564 \\
(3.245)\end{array}$ & $\begin{array}{c}0.0018 \\
(3.074)\end{array}$ & $\begin{array}{l}-0.0015 \\
(-2.440)\end{array}$ & $\begin{array}{c}0.7560 \\
(-4.360)\end{array}$ & 0.0306 \\
\hline Switzerland & 1944 & 1 & $\begin{array}{r}0.2008 \\
(6.863)\end{array}$ & $\begin{array}{l}0.1142 \\
(6.069)\end{array}$ & $\begin{array}{l}0.0005 \\
(1.019)\end{array}$ & $\begin{array}{l}-0.0017 \\
(-2.983)\end{array}$ & $\begin{array}{c}0.6948 \\
(-7.150)\end{array}$ & 0.0370 \\
\hline \multirow[t]{2}{*}{ U.K. } & 1965 & 7 & $\begin{array}{r}0.1708 \\
(3.090)\end{array}$ & $\begin{array}{l}-0.0281 \\
(-1.974)\end{array}$ & $\begin{array}{l}-0.0004 \\
(-1.700)\end{array}$ & $\begin{array}{l}0.0018 \\
(2.873)\end{array}$ & $\begin{array}{c}0.7771 \\
(-3.178)\end{array}$ & 0.0280 \\
\hline & 1968 & 3 & $\begin{array}{l}0.1525 \\
(3.194)\end{array}$ & $\begin{array}{l}-0.0200 \\
(-1.450)\end{array}$ & $\begin{array}{l}-0.0005 \\
(-2.082)\end{array}$ & $\begin{array}{l}0.0020 \\
(2.778)\end{array}$ & $\begin{array}{c}0.8055 \\
(-3.282)\end{array}$ & 0.0280 \\
\hline \multirow[t]{2}{*}{ U.S. } & 1938 & 7 & $\begin{array}{l}0.2180 \\
(4.446)\end{array}$ & $\begin{array}{l}0.0512 \\
(3.197)\end{array}$ & $\begin{array}{l}-0.0003 \\
(-0.547)\end{array}$ & $\begin{array}{l}0.0004 \\
(0.558)\end{array}$ & $\begin{array}{c}0.7419 \\
(-4.579)\end{array}$ & 0.0309 \\
\hline & 1939 & 7 & $\begin{array}{l}0.2291 \\
(4.406)\end{array}$ & $\begin{array}{l}0.0510 \\
(3.010)\end{array}$ & $\begin{array}{l}-0.0002 \\
(-0.267)\end{array}$ & $\begin{array}{l}0.0002 \\
(0.265)\end{array}$ & $\begin{array}{c}0.7261 \\
(-4.580)\end{array}$ & 0.0311 \\
\hline Uruguay & 1961 & 2 & $\begin{array}{l}0.0962 \\
(3.747)\end{array}$ & $\begin{array}{l}-0.1365 \\
(-3.817)\end{array}$ & $\begin{array}{l}-0.0002 \\
(-0.338)\end{array}$ & $\begin{array}{l}-0.0005 \\
(-0.456)\end{array}$ & $\begin{array}{c}0.6208 \\
(-4.930)\end{array}$ & 0.0636 \\
\hline Venezuela & 1943 & 1 & $\begin{array}{l}-0.1838 \\
(-3.998)\end{array}$ & $\begin{array}{c}0.1157 \\
(3.591)\end{array}$ & $\begin{array}{l}0.0061 \\
(3.948)\end{array}$ & $\begin{array}{r}-0.0098 \\
(-4.774)\end{array}$ & $\begin{array}{c}0.8260 \\
(-5.036)\end{array}$ & 0.0666 \\
\hline
\end{tabular}

Notes: The trimming parameter $\lambda_{0}$ is equal to 0.10 in the estimates. Numbers in the parentheses under the estimated trend-function coefficients are the respective $t$-statistics for the null hypothesis that the parameter is equal to zero. The number in parenthesis under the coefficient estimate of the first lag, $\hat{\alpha}$, is the $t$-statistic for the null hypothesis that it is equal to one. 
Table 5. "Trend" Tests for $\beta$-Convergence

\begin{tabular}{|c|c|c|c|c|c|}
\hline Country & Break-Date & Period & Intercept & Trend & Conclusion \\
\hline Argentina & No Break & $1900-2001$ & $0.1166^{\mathrm{a}}$ & $-0.0014^{\mathrm{a}}$ & Converging \\
\hline Australia & No Break & $1900-2001$ & $0.1114^{\mathrm{a}}$ & - & Steady State \\
\hline \multirow[t]{2}{*}{ Austria } & 1953 & 1900-1953 & $0.1958^{\mathrm{a}}$ & $-0.0044^{b}$ & Converging \\
\hline & 1953 & $1954-2001$ & $0.1377^{\mathrm{a}}$ & $0.0052^{\mathrm{b}}$ & Diverging \\
\hline \multirow[t]{2}{*}{ Belgium } & 1939 & 1900-1939 & $0.2472^{\mathrm{a}}$ & -0.0002 & Steady State \\
\hline & 1939 & $1940-2001$ & $0.1278^{\mathrm{a}}$ & $0.0035^{\mathrm{a}}$ & Diverging \\
\hline \multirow[t]{2}{*}{ Brazil } & 1977 & $1900-1977$ & $-0.5760^{\mathrm{a}}$ & $0.0037^{\mathrm{a}}$ & Converging \\
\hline & 1977 & 1978-2001 & $-0.2186^{a}$ & -0.0025 & Steady State \\
\hline \multirow[t]{2}{*}{ Canada } & 1939 & 1900-1939 & $0.2338^{\mathrm{a}}$ & -0.0021 & Steady State \\
\hline & 1939 & $1940-2001$ & $0.2621^{\mathrm{a}}$ & $0.0007^{\mathrm{c}}$ & Diverging \\
\hline \multirow[t]{2}{*}{ Chile } & 1972 & 1900-1972 & 0.0444 & -0.0008 & Steady State \\
\hline & 1972 & 1973-2001 & $-0.1783^{\mathrm{a}}$ & $0.0075^{\mathrm{a}}$ & Converging \\
\hline Columbia & No Break & $1900-2001$ & $-0.0831^{\mathrm{a}}$ & - & Steady State \\
\hline \multirow[t]{2}{*}{ Denmark } & 1939 & 1900-1939 & $0.2855^{\mathrm{a}}$ & $0.0044^{\mathrm{a}}$ & Diverging \\
\hline & 1939 & $1940-2001$ & $0.3368^{\mathrm{a}}$ & $0.0035^{\mathrm{a}}$ & Diverging \\
\hline \multirow[t]{2}{*}{ Finland } & 1918 & $1900-1918$ & 0.0101 & $-0.0092^{\mathrm{a}}$ & Diverging \\
\hline & 1918 & $1919-2001$ & -0.0290 & $0.0031^{\mathrm{b}}$ & Diverging \\
\hline \multirow[t]{2}{*}{ France } & 1939 & 1900-1939 & $0.1333^{\mathrm{a}}$ & 0.0026 & Steady State \\
\hline & 1939 & 1940-2001 & $0.0812^{\mathrm{a}}$ & $0.0052^{\mathrm{a}}$ & Diverging \\
\hline Germany & No Break & $1900-2001$ & $0.0429^{b}$ & $0.0009^{\mathrm{a}}$ & Diverging \\
\hline India & \multicolumn{4}{|c|}{ No evidence of stochastic convergence. } & Diverging \\
\hline \multirow[t]{2}{*}{ Italy } & 1945 & 1900-1945 & $0.0530^{\mathrm{b}}$ & $-0.0024^{\mathrm{c}}$ & Converging \\
\hline & 1945 & 1946-2001 & $0.0534^{\mathrm{a}}$ & 0.0004 & Steady State \\
\hline Japan & \multicolumn{4}{|c|}{ No evidence of stochastic convergence. } & Diverging \\
\hline Mexico & \multicolumn{4}{|c|}{ No evidence of stochastic convergence. } & Diverging \\
\hline \multirow[t]{2}{*}{ Netherlands } & 1939 & 1900-1939 & $0.2234^{\mathrm{a}}$ & 0.0020 & Steady State \\
\hline & 1939 & $1940-2001$ & $0.1532^{\mathrm{a}}$ & $0.0036^{\mathrm{a}}$ & Diverging \\
\hline \multirow[t]{2}{*}{ New Zealand } & 1944 & 1900-1944 & $0.4250^{\mathrm{a}}$ & $-0.0031^{\mathrm{c}}$ & Converging \\
\hline & 1944 & $1945-2001$ & $0.4230^{\mathrm{a}}$ & $-0.0033^{a}$ & Converging \\
\hline \multirow[t]{2}{*}{ Norway } & 1939 & 1900-1939 & -0.0217 & $0.0037^{\mathrm{a}}$ & Diverging \\
\hline & 1939 & $1940-2001$ & $0.0699^{\mathrm{a}}$ & $0.0036^{\mathrm{a}}$ & Diverging \\
\hline Peru & \multicolumn{4}{|c|}{ No evidence of stochastic convergence. } & Diverging \\
\hline
\end{tabular}


Table 5 (Continued). “Trend” Tests for $\beta$-Convergence

\begin{tabular}{|c|c|c|c|c|c|}
\hline Country & Break-Date & Period & Intercept & Trend & Conclusion \\
\hline Portugal & \multicolumn{4}{|c|}{ No evidence of stochastic convergence. } & Diverging \\
\hline \multirow[t]{2}{*}{ Spain } & 1935 & 1900-1935 & $-0.0461^{\mathrm{b}}$ & 0.0017 & Steady State \\
\hline & 1935 & $1936-2001$ & $-0.2082^{\mathrm{a}}$ & $0.0063^{\mathrm{a}}$ & Converging \\
\hline Sri Lanka & \multicolumn{4}{|c|}{ No evidence of stochastic convergence. } & Diverging \\
\hline Sweden & \multicolumn{4}{|c|}{ No evidence of stochastic convergence. } & Diverging \\
\hline \multirow[t]{2}{*}{ Switzerland } & 1944 & $1900-1944$ & $0.2008^{\mathrm{a}}$ & 0.0005 & Steady State \\
\hline & 1944 & $1945-2001$ & $0.3365^{\mathrm{a}}$ & $-0.0012^{\mathrm{a}}$ & Converging \\
\hline U.K. & \multicolumn{4}{|c|}{ No evidence of stochastic convergence. } & Diverging \\
\hline U.S. & No Break & $1900-2001$ & $0.1383^{\mathrm{a}}$ & $0.0004^{\mathrm{b}}$ & Diverging \\
\hline \multirow[t]{2}{*}{ Uruguay } & 1961 & $1900-1961$ & $0.0962^{\mathrm{a}}$ & -0.0002 & Steady State \\
\hline & 1961 & $1962-2001$ & $-0.0521^{b}$ & -0.0007 & Steady State \\
\hline \multirow[t]{2}{*}{ Venezuela } & 1943 & $1900-1943$ & $-0.1838^{\mathrm{a}}$ & $0.0061^{\mathrm{a}}$ & Converging \\
\hline & 1943 & 1944-2001 & $0.1881^{\mathrm{a}}$ & $-0.0037^{\mathrm{a}}$ & Converging \\
\hline
\end{tabular}

Notes: To be considered "converging" in a given period, a country's relative income series must (1) reject the null hypothesis of a unit root to confirm that stochastic convergence is occurring (as reported in Tables 1 and 3); and (2) have statistically significant intercept and trend coefficient estimates of opposite signs. "Steady state" indicates that convergence has occurred and the country has reached its steady state in the given period, as indicated by a trend coefficient that is insignificantly different from zero. All other instances are denoted as “diverging.” Superscripts 'a,' 'b,' and 'c' indicate significance at the $1 \%, 5 \%$, and $10 \%$ levels, respectively. Significance levels are based on simulated critical values for the null hypothesis that the estimated coefficient equals zero in the Mixed Model unit-root test equation for countries with breaks; see the discussion in the text for details. For countries without breaks, standard critical values on coefficients estimated in ADF test equations apply. 
Table 6A. “Trend” Tests for $\beta$-Convergence: OECD Club

\begin{tabular}{|c|c|c|c|c|c|}
\hline Country & Break-Date & Period & Intercept & Trend & Conclusion \\
\hline Austria & No Break & $1900-2001$ & $-0.0318^{\mathrm{a}}$ & - & Steady State $^{+}$ \\
\hline Australia & \multicolumn{4}{|c|}{ No evidence of stochastic convergence. } & Diverging - \\
\hline \multirow[t]{2}{*}{ Belgium } & 1939 & $1900-1939$ & $0.0494^{\mathrm{c}}$ & -0.0006 & Steady State \\
\hline & 1939 & $1940-2001$ & $-0.0663^{\mathrm{a}}$ & 0.0006 & Steady State ${ }^{+}$ \\
\hline \multirow[t]{2}{*}{ Canada } & 1939 & 1900-1939 & $0.0564^{\mathrm{b}}$ & $-0.0022^{c}$ & Converging \\
\hline & 1939 & $1940-2001$ & $0.0772^{\mathrm{a}}$ & $-0.0016^{\mathrm{a}}$ & Converging ${ }^{+}$ \\
\hline \multirow[t]{2}{*}{ Denmark } & 1939 & 1900-1939 & -0.0073 & $0.0028^{\mathrm{b}}$ & Diverging \\
\hline & 1939 & 1940-2001 & 0.0245 & -0.0003 & Steady State ${ }^{+}$ \\
\hline \multirow[t]{2}{*}{ Finland } & 1918 & $1900-1918$ & -0.0843 & $-0.0074^{\mathrm{a}}$ & Diverging \\
\hline & 1918 & 1919-2001 & $-0.0986^{c}$ & 0.0010 & Steady State ${ }^{+}$ \\
\hline France & No Break & $1900-2001$ & $-0.0207^{\mathrm{a}}$ & - & Steady State $^{+}$ \\
\hline Germany & No Break & $1900-2001$ & $-0.0134^{c}$ & - & Steady State $^{+}$ \\
\hline \multirow[t]{2}{*}{ Italy } & 1945 & 1900-1945 & 0.0063 & $-0.0026^{b}$ & Diverging - \\
\hline & 1945 & 1946-2001 & -0.0001 & -0.0004 & Steady State \\
\hline Japan & \multicolumn{4}{|c|}{ No evidence of stochastic convergence. } & Diverging \\
\hline \multirow[t]{2}{*}{ Netherlands } & 1939 & 1900-1939 & 0.0235 & 0.0016 & Steady State \\
\hline & 1939 & 1940-2001 & -0.0479 & 0.0007 & Steady State ${ }^{+}$ \\
\hline \multirow[t]{2}{*}{ New Zealand } & 1944 & 1900-1944 & $0.2037^{\mathrm{a}}$ & $-0.0038^{\mathrm{a}}$ & Converging \\
\hline & 1944 & 1945-2001 & $0.1778^{\mathrm{a}}$ & $-0.0067^{\mathrm{a}}$ & Converging \\
\hline \multirow[t]{2}{*}{ Norway } & 1938 & $1900-1938$ & $-0.1604^{\mathrm{a}}$ & $0.0036^{\mathrm{a}}$ & Converging ${ }^{+}$ \\
\hline & 1938 & 1939-2001 & $-0.0733^{b}$ & $0.0016^{\mathrm{b}}$ & Converging ${ }^{+}$ \\
\hline \multirow[t]{2}{*}{ Portugal } & 1938 & $1900-1938$ & $-0.3689^{a}$ & 0.0008 & Steady State \\
\hline & 1938 & 1939-2001 & $-0.4130^{\mathrm{a}}$ & $0.0041^{\mathrm{a}}$ & Converging \\
\hline \multirow[t]{2}{*}{ Spain } & 1935 & $1900-1935$ & $-0.2206^{\mathrm{a}}$ & 0.0016 & Steady State \\
\hline & 1935 & $1936-2001$ & $-0.3916^{\mathrm{a}}$ & $0.0042^{\mathrm{a}}$ & Converging \\
\hline \multirow[t]{2}{*}{ Sweden } & 1944 & 1900-1944 & $-0.0674^{\mathrm{a}}$ & 0.0012 & Steady State ${ }^{+}$ \\
\hline & 1944 & 1945-2001 & $0.0488^{\mathrm{a}}$ & $-0.0016^{\mathrm{a}}$ & Converging ${ }^{+}$ \\
\hline \multirow[t]{2}{*}{ Switzerland } & 1944 & $1900-1944$ & $0.0604^{\mathrm{a}}$ & 0.0000 & Steady State \\
\hline & 1944 & $1945-2001$ & $0.1738^{a}$ & $-0.0033^{\mathrm{a}}$ & Converging \\
\hline U.K. & \multicolumn{4}{|c|}{ No evidence of stochastic convergence. } & Diverging \\
\hline \multirow[t]{2}{*}{ U.S. } & 1939 & 1900-1939 & $0.1252^{\mathrm{a}}$ & -0.0009 & Steady State ${ }^{+}$ \\
\hline & 1939 & $1940-2001$ & $0.1627^{\mathrm{a}}$ & $-0.0020^{\mathrm{a}}$ & Converging $^{+}$ \\
\hline
\end{tabular}

Notes: To be considered "converging” in a given period, a country's relative income series must (1) reject the null hypothesis of a unit root to confirm that stochastic convergence is occurring; and (2) have statistically significant intercept and trend coefficient estimates of opposite signs. "Steady state" indicates that convergence has occurred and the country has reached its steady state in the given period, as indicated by a trend coefficient that is insignificantly different from zero. All other instances are denoted as "diverging." Superscripts 'a,' 'b,' and 'c' indicate significance at the $1 \%, 5 \%$, and $10 \%$ levels, respectively. Significance levels are based on simulated critical values for the null hypothesis that the estimated coefficient equals zero in the Mixed Model unit-root test equation for countries with breaks; see the discussion in the text for details. For countries without breaks, standard critical values on coefficients estimated in ADF test equations apply. Superscript + (-) indicates instances where there is more (less) evidence of convergence or having already reached a steady state than was found in the analysis of the full sample (as reported in Table 5). 
Table 6B. “Trend” Tests for $\beta$-Convergence: European Club

\begin{tabular}{|c|c|c|c|c|c|}
\hline Country & Break-Date & Period & Intercept & Trend & Conclusion \\
\hline \multirow[t]{2}{*}{ Austria } & 1953 & $1900-1953$ & -0.0162 & $-0.0052^{\mathrm{a}}$ & Diverging $^{-}$ \\
\hline & 1953 & 1954-2001 & $-0.1163^{c}$ & $0.0033^{c}$ & Converging ${ }^{+}$ \\
\hline \multirow[t]{2}{*}{ Belgium } & 1918 & 1900-1918 & $0.0979^{\mathrm{a}}$ & $-0.0074^{a}$ & Converging \\
\hline & 1918 & 1919-2001 & $0.0496^{\mathrm{b}}$ & $-0.0007^{c}$ & Converging ${ }^{+}$ \\
\hline \multirow[t]{2}{*}{ Denmark } & 1953 & 1900-1953 & $0.0363^{c}$ & $0.0022^{\mathrm{a}}$ & Diverging \\
\hline & 1953 & 1954-2001 & $0.1071^{\mathrm{a}}$ & -0.0011 & Steady State ${ }^{+}$ \\
\hline \multirow[t]{2}{*}{ Finland } & 1918 & $1900-1918$ & -0.0621 & $-0.0060^{\mathrm{b}}$ & Diverging \\
\hline & 1918 & $1919-2001$ & -0.0498 & 0.0007 & Steady State ${ }^{+}$ \\
\hline \multirow[t]{2}{*}{ France } & 1944 & $1900-1944$ & 0.0182 & -0.0017 & Steady State \\
\hline & 1944 & $1945-2001$ & 0.0294 & -0.0003 & Steady State ${ }^{+}$ \\
\hline Germany & No Break & $1900-2001$ & -0.0048 & $0.0005^{\mathrm{c}}$ & Diverging \\
\hline Italy & No Break & $1900-2001$ & $-0.0585^{\mathrm{a}}$ & $0.0006^{\mathrm{a}}$ & Converging \\
\hline Netherlands & No Break & $1900-2001$ & $0.0574^{\mathrm{a}}$ & $-0.0004^{c}$ & Converging ${ }^{+}$ \\
\hline Norway & \multicolumn{4}{|c|}{ No evidence of stochastic convergence. } & Diverging \\
\hline \multirow[t]{2}{*}{ Portugal } & 1969 & 1900-1969 & $-0.4424^{\mathrm{a}}$ & $0.0015^{\mathrm{a}}$ & Converging \\
\hline & 1969 & $1970-2001$ & $-0.2781^{b}$ & $0.0039^{\mathrm{b}}$ & Converging \\
\hline \multirow[t]{2}{*}{ Spain } & 1935 & 1900-1935 & $-0.1688^{\mathrm{a}}$ & 0.0011 & Steady State \\
\hline & 1935 & 1936-2001 & $-0.2888^{\mathrm{a}}$ & $0.0034^{\mathrm{a}}$ & Converging \\
\hline \multirow[t]{2}{*}{ Sweden } & 1941 & $1900-1941$ & $-0.0524^{\mathrm{a}}$ & $0.0016^{\mathrm{c}}$ & Converging $^{+}$ \\
\hline & 1941 & 1942-2001 & $0.0894^{\mathrm{a}}$ & $-0.0016^{\mathrm{a}}$ & Converging $^{+}$ \\
\hline \multirow[t]{2}{*}{ Switzerland } & 1944 & $1900-1944$ & $0.1169^{\mathrm{a}}$ & $0.0020^{\mathrm{a}}$ & Diverging \\
\hline & 1944 & $1945-2001$ & $0.3933^{\mathrm{a}}$ & $-0.0061^{\mathrm{a}}$ & Converging \\
\hline U.K. & \multicolumn{4}{|c|}{ No evidence of stochastic convergence. } & Diverging \\
\hline
\end{tabular}

Notes: To be considered "converging” in a given period, a country's relative income series must (1) reject the null hypothesis of a unit root to confirm that stochastic convergence is occurring; and (2) have statistically significant intercept and trend coefficient estimates of opposite signs. "Steady state" indicates that convergence has occurred and the country has reached its steady state in the given period, as indicated by a trend coefficient that is insignificantly different from zero. All other instances are denoted as "diverging." Superscripts 'a,' 'b,' and 'c' indicate significance at the 1\%, 5\%, and 10\% levels, respectively. Significance levels are based on simulated critical values for the null hypothesis that the estimated coefficient equals zero in the Mixed Model unit-root test equation for countries with breaks; see the discussion in the text for details. For countries without breaks, standard critical values on coefficients estimated in ADF test equations apply. Superscript $+(-)$ indicates instances where there is more (less) evidence of convergence or having already reached a steady state than was found in the analysis of the full sample (as reported in Table 5). 
Table 6C. “Trend” Tests for $\beta$-Convergence: Latin American Club

\begin{tabular}{|c|c|c|c|c|c|}
\hline Country & Break-Date & Period & Intercept & Trend & Conclusion \\
\hline Argentina & No Break & $1900-2001$ & $0.1927^{\mathrm{a}}$ & $-0.0015^{\mathrm{a}}$ & Converging \\
\hline \multirow[t]{2}{*}{ Brazil } & 1970 & $1900-1970$ & $-0.2446^{a}$ & $0.0017^{\mathrm{a}}$ & Converging \\
\hline & 1970 & 1971-2001 & -0.0616 & 0.0007 & Steady State \\
\hline \multirow[t]{2}{*}{ Chile } & 1972 & 1900-1972 & $0.2081^{\mathrm{a}}$ & $-0.0015^{\mathrm{a}}$ & Converging \\
\hline & 1972 & 1973-2001 & $-0.1076^{a}$ & $0.0110^{\mathrm{a}}$ & Converging \\
\hline Columbia & No Break & $1900-2001$ & $-0.0314^{\mathrm{a}}$ & - & Steady State \\
\hline \multirow[t]{2}{*}{ Mexico } & 1926 & $1900-1926$ & $0.0482^{\mathrm{b}}$ & -0.0008 & Steady State ${ }^{+}$ \\
\hline & 1926 & $1927-2001$ & $-0.0636^{\mathrm{a}}$ & $0.0015^{\mathrm{a}}$ & Converging $^{+}$ \\
\hline Peru & \multicolumn{4}{|c|}{ No evidence of stochastic convergence. } & Diverging \\
\hline Uruguay & \multicolumn{4}{|c|}{ No evidence of stochastic convergence. } & Diverging \\
\hline Venezuela & \multicolumn{4}{|c|}{ No evidence of stochastic convergence. } & Diverging \\
\hline \multicolumn{6}{|c|}{$\begin{array}{l}\text { Notes: To be considered "converging" in a given period, a country's relative income series must (1) reject the null hypothesis of a unit } \\
\text { root to confirm that stochastic convergence is occurring; and (2) have statistically significant intercept and trend coefficient estimates } \\
\text { of opposite signs. "Steady state" indicates that convergence has occurred and the country has reached its steady state in the given period, } \\
\text { as indicated by a trend coefficient that is insignificantly different from zero. All other instances are denoted as "diverging." Superscripts } \\
\text { 'a,' 'b,' and 'c' indicate significance at the } 1 \%, 5 \% \text {, and } 10 \% \text { levels, respectively. Significance levels are based on simulated critical } \\
\text { values for the null hypothesis that the estimated coefficient equals zero in the Mixed Model unit-root test equation for countries with } \\
\text { breaks; see the discussion in the text for details. For countries without breaks, standard critical values on coefficients estimated in ADF } \\
\text { test equations apply. Superscript }+(-) \text { indicates instances where there is more (less) evidence of convergence or having already reached } \\
\text { a steady state than was found in the analysis of the full sample (as reported in Table } 5 \text { ). }\end{array}$} \\
\hline
\end{tabular}




\section{References}

Banerjee A, Lumsdaine RL, Stock JH (1992) Recursive and Sequential Tests of the Unit-Root and Trend-Break Hypothesis: Theory and International Evidence. Journal of Business and Economic Statistics 10: 271-287.

Barro RJ (1991) Economic Growth in a Cross Section of Countries. Quarterly Journal of Economics 106: 407-443.

Barro RJ, Sala-i-Martin X (1992) Convergence. Journal of Political Economy 100: 223-251.

Baumol WJ (1986) Productivity Growth, Convergence, and Welfare: What the Long-Run Data Show. American Economic Review 76: 1075-1085.

Carlino G, Mills L (1993) Are U.S. Regional Economies Converging? A Time Series Analysis. Journal of Monetary Economics 32: 335-346.

deJuan JP, Tomljanovich M (2005) Income Convergence Across Canadian Provinces in the $20^{\text {th }}$ Century: Almost But Not Quite There. Annals of Regional Science 39: 567-592.

Friedman M (1992) Do Old Fallacies Ever Die? Journal of Economic Literature 30: 2129-2132.

Hopenhayn HA, Neumeyer PA (2004) Latin America in the XXth Century: Stagnation, then Collapse. Working Paper, Department of Economics, University of California, Los Angeles.

Hotelling H (1933) Review of The Triumph of Mediocrity in Business by Horace Sechrist. Journal of the American Statistical Association 28: 463-65.

Li Q, Papell D (1999) Convergence of International Output: Time Series Evidence for 16 OECD Countries. International Review of Economics and Finance 8: 267-280.

Loewy MB, Papell DH (1996) Are U.S. Regional Incomes Converging? Some Further Evidence. Journal of Monetary Economics 38: 587-598.

Maddison A (1995) Monitoring the World Economy: 1820-1992. OECD Development Center, Paris, France.

Maddison A (2003) The World Economy: Historical Statistics. Development Center for OECD, Paris, France.

Murray CJ, Zivot E (1998) Inference on Unit Roots and Trend Breaks in Macroeconomic Time Series. Manuscript, Department of Economics, University of Houston.

Nieswiadomy ML, Strazicich MC (2004) Are Political Freedoms Converging? Economic Inquiry 42: 
323-340.

Perron P (1989) The Great Crash, the Oil Price Shock and the Unit Root Hypothesis. Econometrica 55: 1035-1401.

Perron P (1997) Further Evidence on Breaking Trend Functions in Macroeconomic Variables. Journal of Econometrics 80: 355-385.

Perron P, Vogelsang TJ (1992) Nonstationarity and Level Shifts With an Application to Purchasing Power Parity. Journal of Business and Economic Statistics 10: 301-320.

Sen A (2003) On Unit Root Tests When the Alternative is a Trend-Break Stationary Process. Journal of Business and Economic Statistics 21: 174-184.

Sen A (2005) Some Aspects of the Unit-Root Testing Methodology with Application to Macroeconomic Time Series. Manuscript, Department of Economics, Xavier University, Cincinnati, OH.

Solow RM (1956) A Contribution to the Theory of Economic Growth. Quarterly Journal of Economics 70: 65-94.

Strazicich MC, Lee J, Day E (2004) Are Incomes Converging Among OECD Countries? Time Series Evidence with Two Structural Breaks. Journal of Macroeconomics 26: 131-145.

Tomljanovich M, Vogelsang TJ (2002) Are U.S. Regions Converging? Using New Econometric Models to Examine Old Issues. Empirical Economics 27: 49-62.

Vogelsang TJ, Perron P (1998) Additional Tests for a Unit Root Allowing for a Break in the Trend Function at an Unknown Time. International Economic Review 39: 1073-1100.

Zivot E, Andrews DWK (1992) Further Evidence on the Great Crash, the Oil-Price Shock, and the UnitRoot Hypothesis. Journal of Business and Economic Statistics 10: 251-270. 


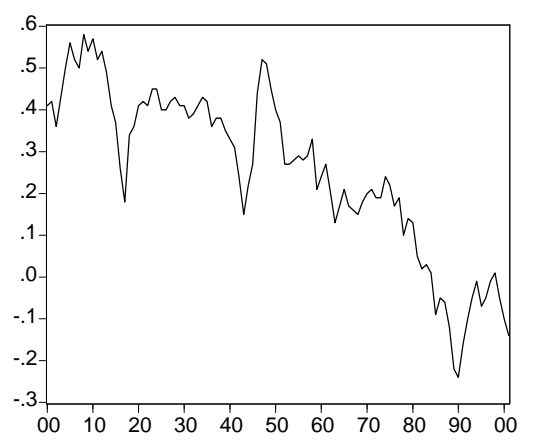

Figure 1: Relative per capital income in Argentina, 1900-2001

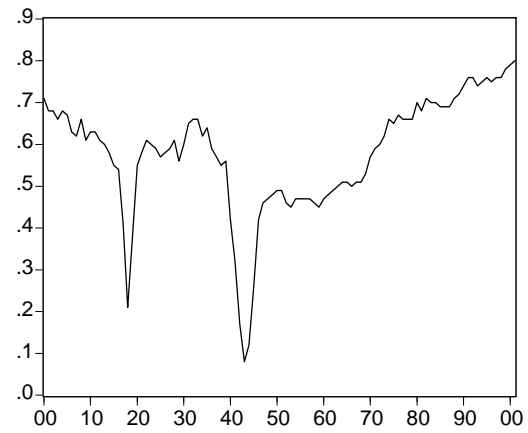

Figure 4: Relative per capital income in Belgium, 1900-2001
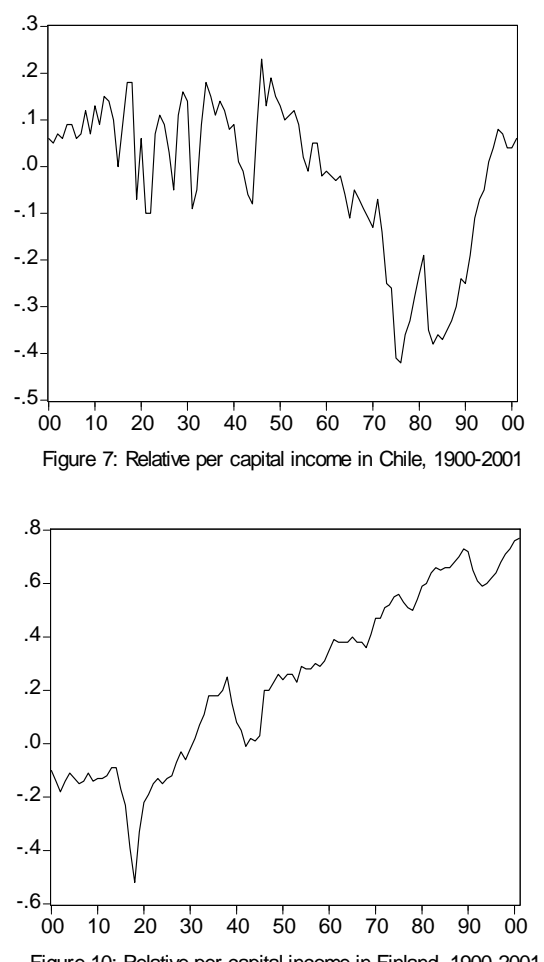

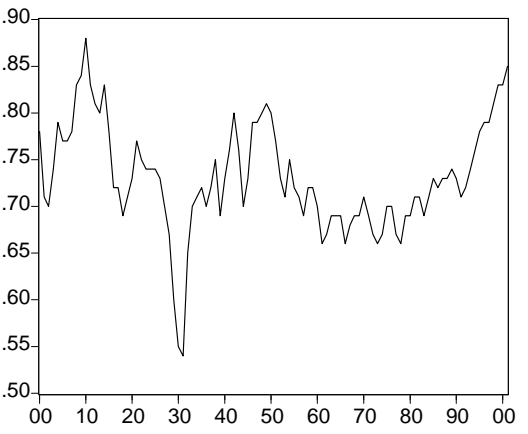

Figure 2: Relative per capital income in Australia, 1900-2001
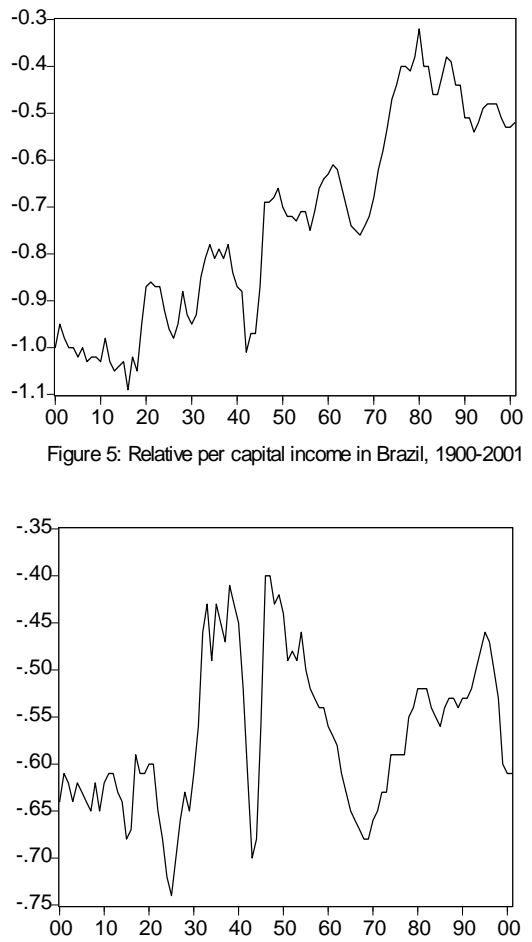

Figure 8: Relative per capital income in Columbia, 1900-2001

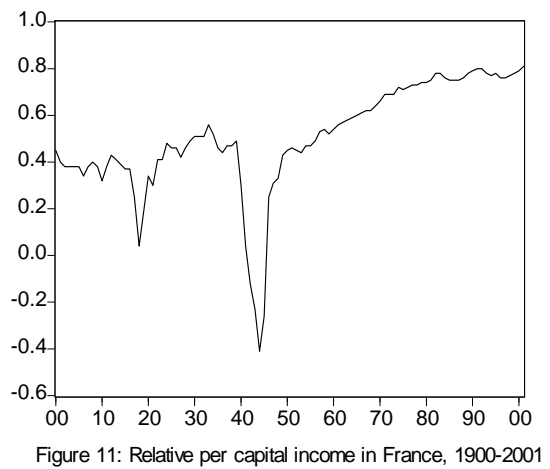

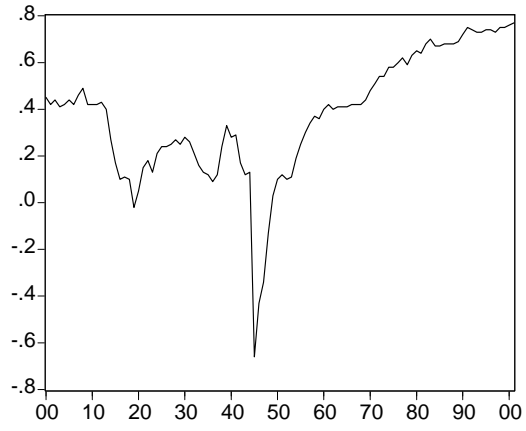

Figure 3: Relative per capital income in Austria, 1900-2001

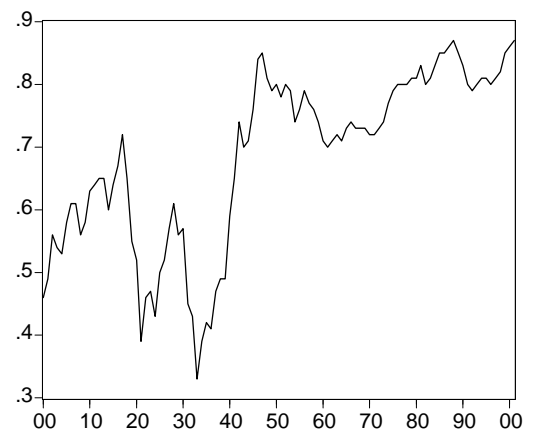

Figure 6: Relative per capital income in Canada, 1900-2001
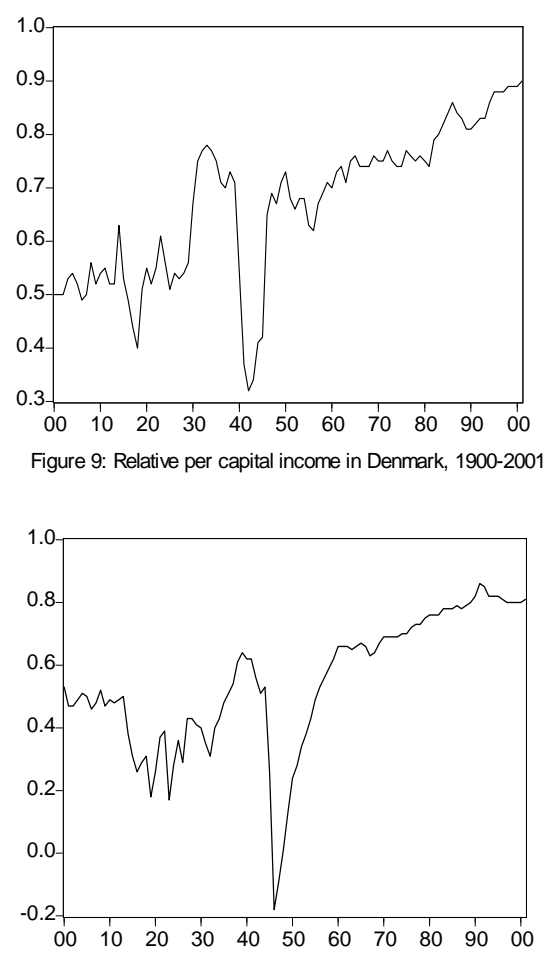

Figure 12: Relative per capital income in Germany, 1900-2001 

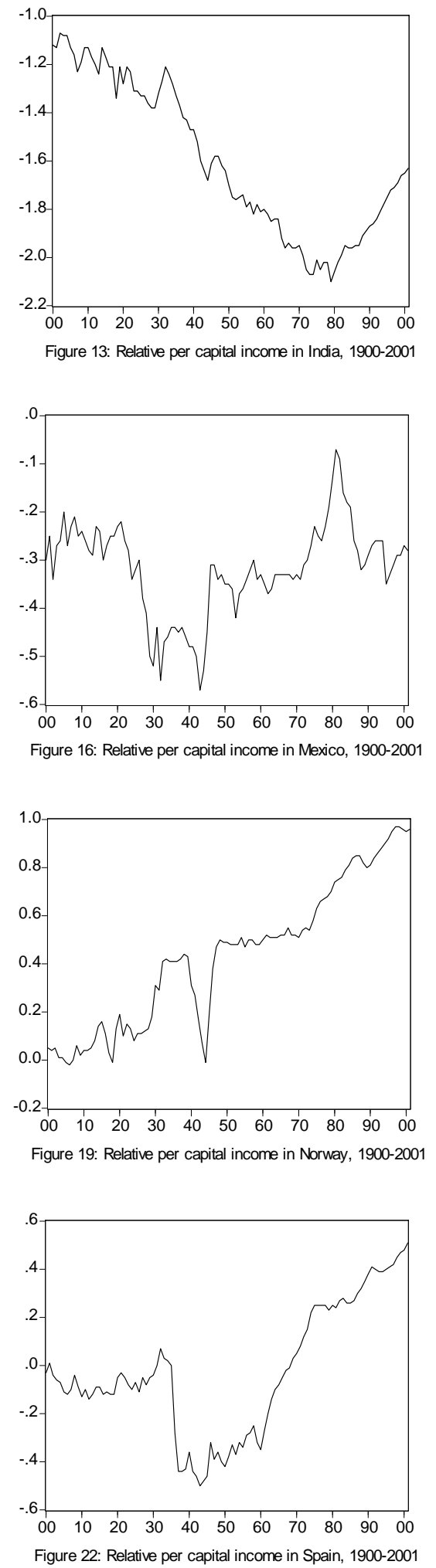
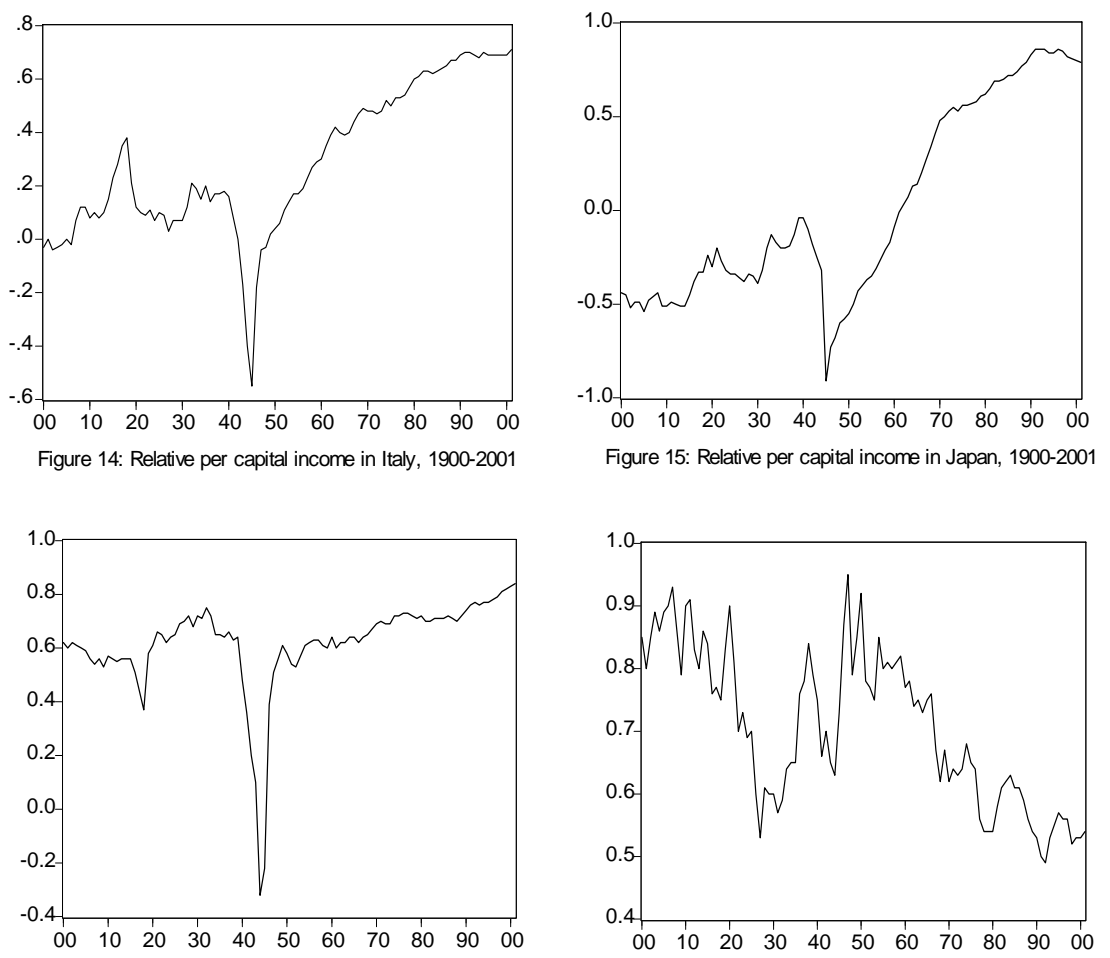

Figure 17: Relative per capital income in Netherlands, 1900-2001
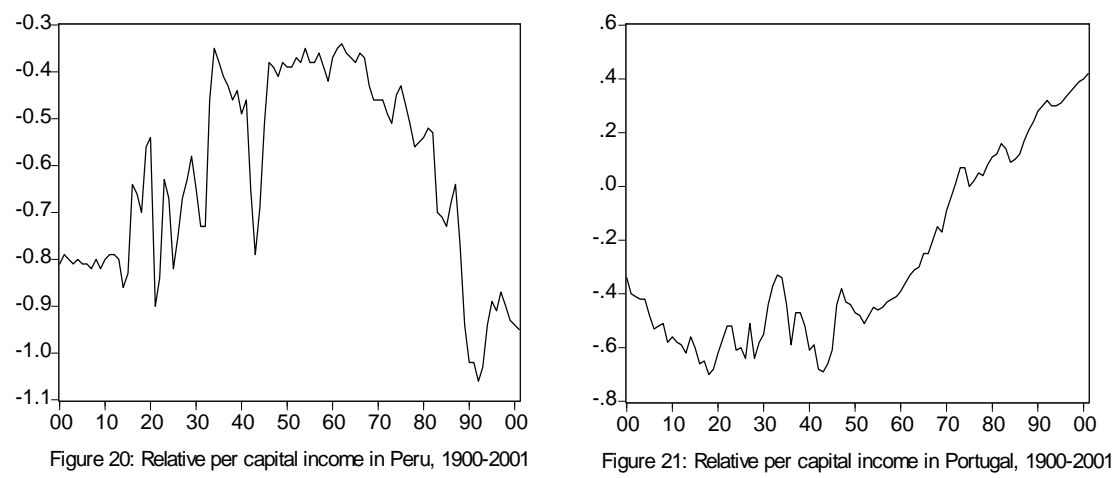

Figure 21: Relative per capital income in Portugal, 1900-2001

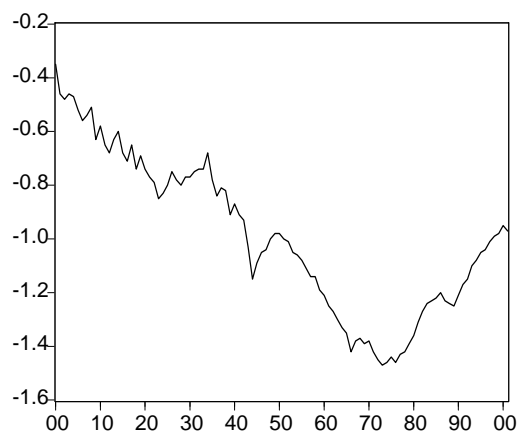

Figure 23: Relative per capital income in Sri Lanka, 1900-2001

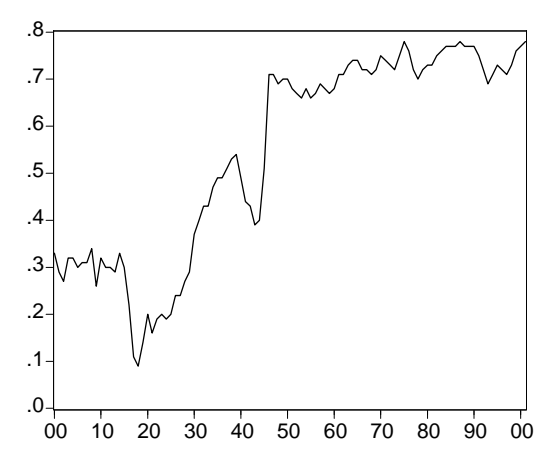

Figure 24: Relative per capital income in Sweden, 1900-2001 


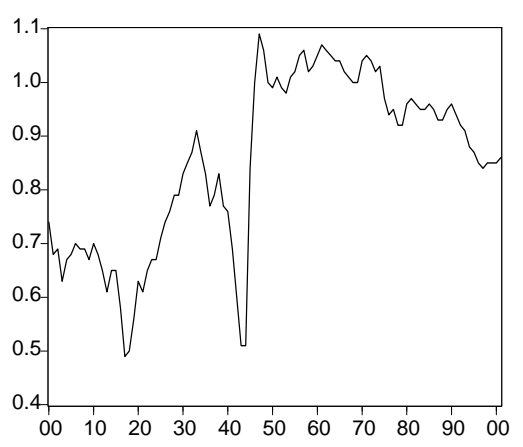

Figure 25: Relative per capital income in Switzerland, 1900-2001

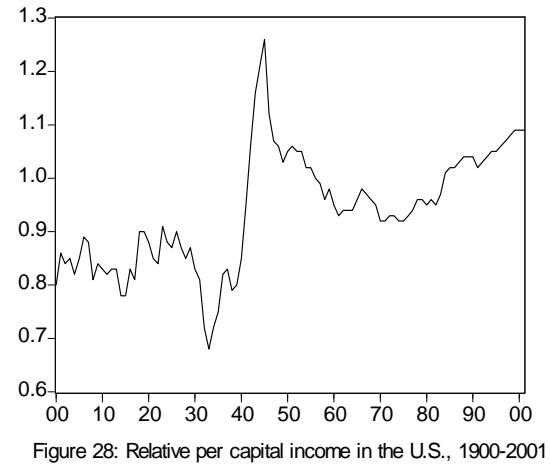

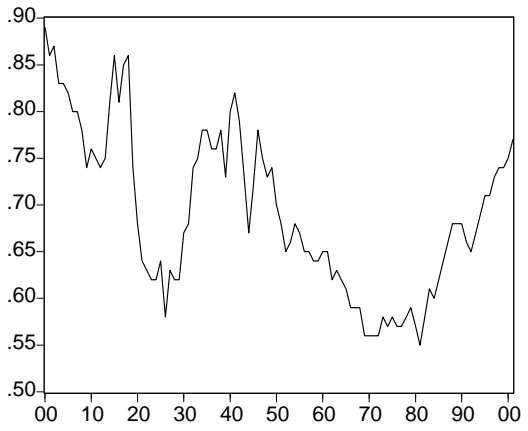

Figure 26: Relative per capital income in the U.K., 1900-2001
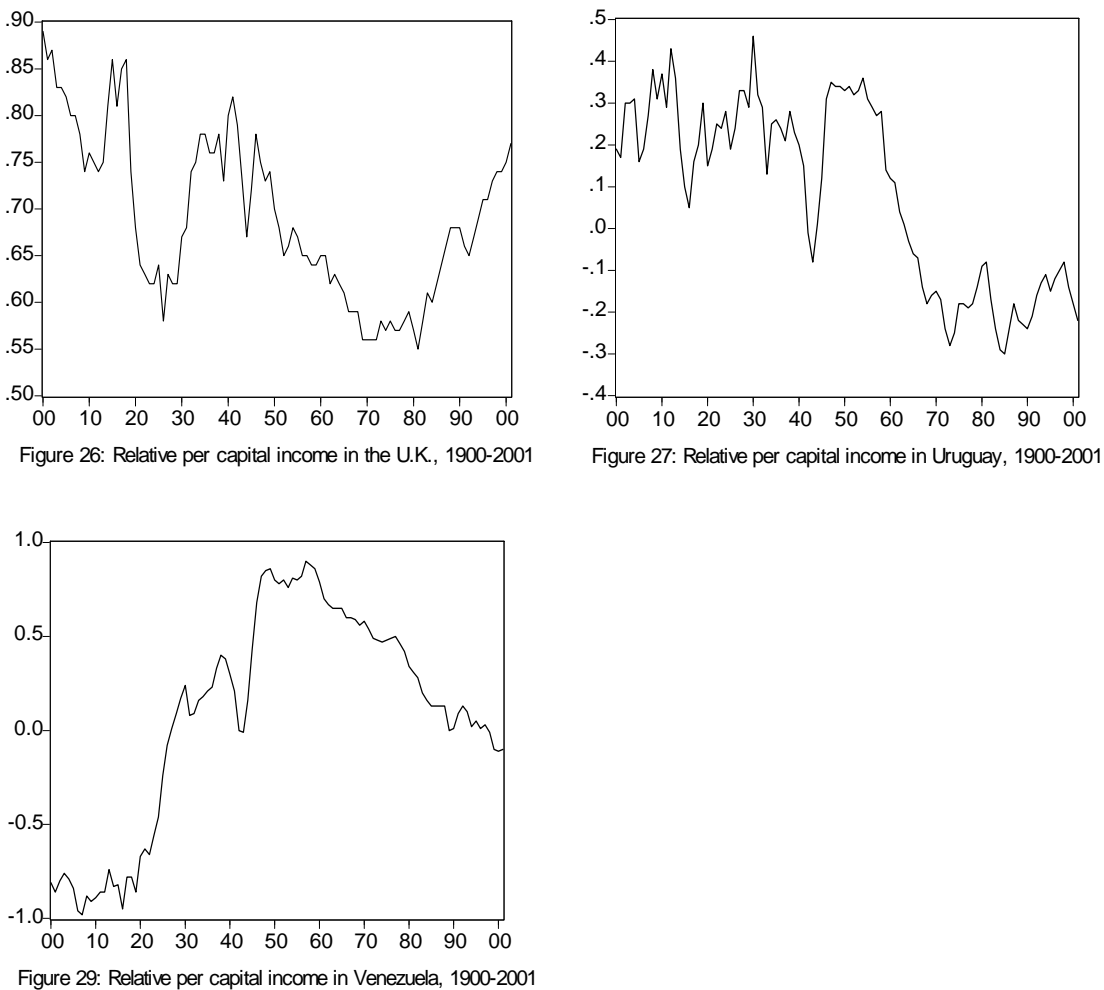

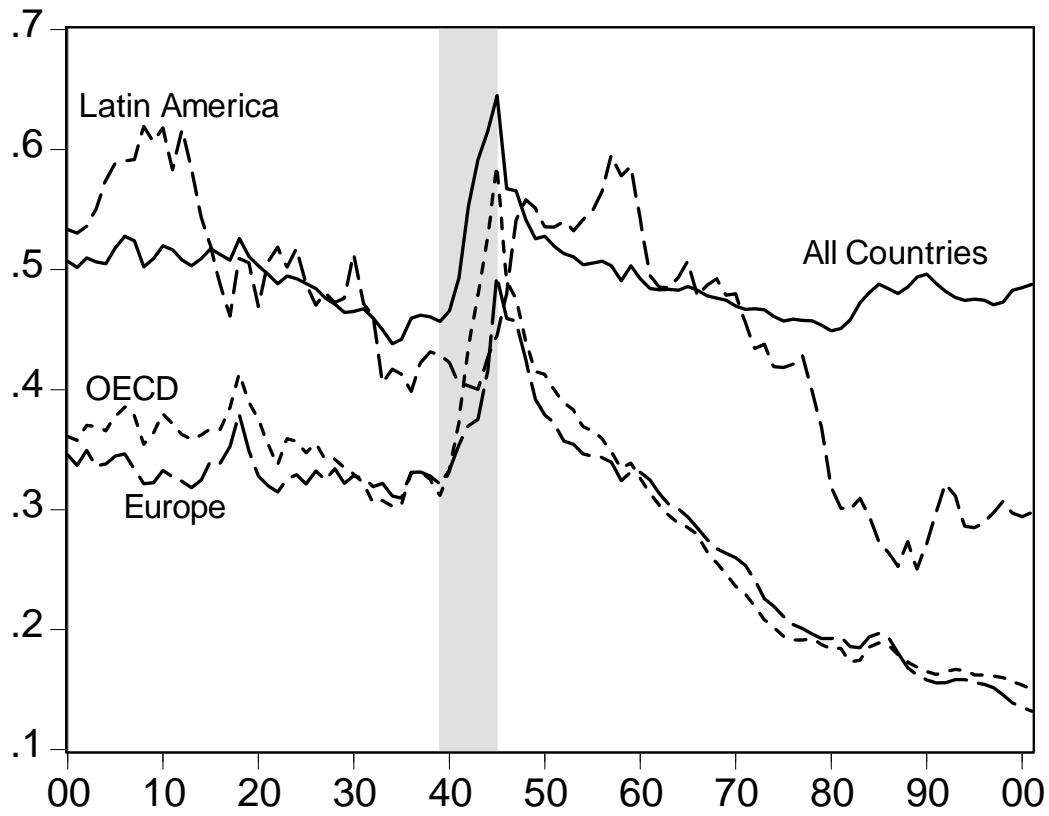

Figure 30: Coefficient of Variation of Real Per Capita GDP (World War II Period 1939-1945 Shaded) 